\title{
Microstructural evolution of Nimonic 80a during hot forging under non-isothermal conditions of screw press
}

\author{
Marcos Perez \\ Advanced Forming Research Centre, University of Strathclyde, 85 Inchinnan Drive, Inchinnan, \\ Renfrew (UK), PA4 9LJ. \\ Corresponding author: Tel: +44 (0) 1415345524 \\ E-mail address: marcos.perez@strath.ac.uk
}

\begin{abstract}
The microstructural evolution of nickel base superalloy Nimonic 80a during hot forging was studied in order to explore the suitability of this alloy to be hot forged under non-isothermal conditions of screw press, considering aspects such as deformation inhomogeneity, flow localization and shear bands formation. Hot forging trials in screw press with double truncated cones were carried out at three different temperatures, 950,1050 \& $1150{ }^{\circ} \mathrm{C}$. The microstructure in the as-preheated condition was analysed in order to understand the impact of soaking temperature on the evolution of both grain size and precipitates/carbides prior to hot forging operations. In the as-forged condition, the impact of forging temperature, strain, strain rate and chilling effect of the dies on the microstructural evolution of Nimonic 80a was studied. No evidences of shear bands or flow localisation associated to adiabatic heating were found in the hot forged double truncated cones, indicating the suitability of Nimonic 80 a to be processed in screw press. However, the non-isothermal conditions of screw press resulted into the development of heterogeneous structures across the thickness. Highly or fully unrecrystallized structures were observed in those areas in contact with bottom die, in contrast with top positions, where highly recrystallized structures were found. Soaking treatments play a very important role on microstructural evolution during hot forging for Nimonic 80a due to its strong impact on both grain growth and dissolution/precipitation of precipitates/carbides. For the present work, discontinuous dynamic recrystallization (DDRX) was found to be the main recrystallization mechanism for Nimonic 80a. Clear evidences of nucleation of new DRX grains by the formation of bulges in serrated grain boundaries with the subsequent growth by twinning were observed at the three forging temperatures. Particle-stimulated nucleation mechanism (PSN) is also operating in Nimonic 80a enhancing the heterogeneous nucleation of new grains in the interior of deformed grains.
\end{abstract}

\section{KEYWORDS}

Hot forging, nickel base superalloy, Nimonic 80a, discontinuous dynamic recrystallization (DDRX), non-isothermal conditions. 


\section{INTRODUCTION}

Nimonic 80a is a wrought, age-hardenable nickel-based superalloy, strengthened by the addition of titanium, aluminium and carbon. Nimonic 80a due to its specific material properties such as high strength at elevated temperatures is used for high temperature applications, such as turbine blades in some industrial gas turbine engines, being one of the most important components of turbine engines (Salehi et al., 2015).

Screw press is characterised by relative high working speeds $(0.5-1.5 \mathrm{~m} / \mathrm{s})$, in direct comparison to hydraulic press $(0.01-1 \mathrm{~m} / \mathrm{s})$ (Dieter et al., 2004). The hot forging of complicated geometries under screw press cause inhomogeneous distribution of deformation parameters such as strain, strain rate and temperature. Deformation inhomogeneity is more critical when the hot forging is done in non-isothermal conditions, due to large surface contact of deforming hot material with the cold die (Salehi et al., 2015). The deformation inhomogeneity may cause flow localization and shear band formation. The severity of the flow localization determines the suitability of screw press forging for a given alloy and/or geometry. Despite the potential occurrence of these defects, nonisothermal screw press forging due to both lower cost and higher production rate is extensively used in the metal forming industry (Salehi et al., 2015). Screw press is commonly applied to nickel base superalloys with low fraction of $\gamma^{\prime}$ precipitates, such as Nimonic 80a and Inconel 718. Conventional forging practice for these nickel-based alloys consists of forging from, and solution heat treating at, temperatures well in excess of $\gamma^{\prime}$ solvus temperature. Hightemperature solution treatment dissolves all the $\gamma^{\prime}$, anneals the matrix and enhances the forgeability (Dieter et al., 2004).

The hot deformation behaviour of Nimonic 80a has been studied by several authors by means of isothermal hot compression tests. Bombac et al. $(2008,2009)$ analysed the hot deformation behaviour and microstructural evolution for temperatures ranging between $950-1120{ }^{\circ} \mathrm{C}$ with strain rates up to $5 \mathrm{~s}^{-1}$. Similar work is reported by Hwang et al. (2014) for a temperature range of $900-1200{ }^{\circ} \mathrm{C}$ with strain rates up to $20 \mathrm{~s}^{-1}$; $\mathrm{Kim}$ et al. (2001) studied the hot forging conditions of Nimonic 80 a at temperatures from 950 to $1200{ }^{\circ} \mathrm{C}$ and strain rates up to 5 $\mathrm{s}^{-1}$; and Srinivasa and Prasad (1995) published the flow stresses of Nimonic 80a for strain rates up to $100 \mathrm{~s}^{-1}$ and for similar temperature ranges $\left(850-1200{ }^{\circ} \mathrm{C}\right)$. On the other hand, Tian et al. (2004) investigated the dynamic recrystallization and dynamic recovery of Nimonic 80a by Gleeble experiments in samples deformed at constant temperature $\left(1055^{\circ} \mathrm{C}\right)$ and at three strain rates $\left(0.1,1\right.$ and $\left.5 \mathrm{~s}^{-1}\right)$. The same author also analysed the influence of $\mathrm{Cr}_{23} \mathrm{C}_{6}$ carbides on dynamic recrystallization of Nimonic 80a by inducing $\gamma^{\prime}$ and carbide precipitates by aging at $800{ }^{\circ} \mathrm{C}$ for 1 hour prior to hot deformation at $1055^{\circ} \mathrm{C}$ (Tian et al., 2003a). In another paper, this latter author 
investigated the influence of the recrystallization degree in samples deformed at $1055^{\circ} \mathrm{C}$ on the kinetics of $\mathrm{Cr}_{23} \mathrm{C}_{6}$ carbide precipitation at $800{ }^{\circ} \mathrm{C}$ (Tian et al., 2003b).

Despite of the amount of published work reporting the hot deformation behaviour and the corresponding microstructural development for Nimonic 80a, most of this research work has been conducted on small compression samples deformed at low strain rates, up to $5 \mathrm{~s}^{-1}$. These conditions are far to be representative of screw press forging, in which high die speeds, and therefore, high strain rates are applied. Similar conclusions can be said about the limited work reporting the impact of non-isothermal conditions on the microstructural evolution of Nimonic 80a.

The presence of precipitates/carbides in the as-preforged condition presents a strong effect not only the grain growth behaviour during soaking treatments, but also on the subsequent mechanisms which control the microstructural evolution during hot forging. Gamma prime $\left(\gamma^{\prime}\right)$ is the main strengthening phase for Nimonic $80 a$, but the presence of carbides such as $M C, M_{23} C_{6}$ and $M_{7} C_{3}$ is also reported in literature for this alloy (Tian et al., 2003b). Voice and Faulkner (1985) determined experimentally the proportions of carbides and carbonitride phases in the solution treatment regime. At temperatures below $1050{ }^{\circ} \mathrm{C}$, both coarse and fine grains are observed, despite of the presence of second phase particles. In the range 1060 to $1150{ }^{\circ} \mathrm{C}$, above $1080{ }^{\circ} \mathrm{C}$ a structure void of $\mathrm{M}_{23} \mathrm{C}_{6}$ particles was found, leaving constrain of grain growth to the remaining $\mathrm{M}_{7} \mathrm{C}_{3}$, and the few $\mathrm{Ti}(\mathrm{C}, \mathrm{N})$ particles present. From 1150 to $1250{ }^{\circ} \mathrm{C}$, large equiaxed grain were observed in samples heat treated at $1150^{\circ} \mathrm{C}$ and above. Grain growth is normal and opposed only by still undissolved $\mathrm{M}_{7} \mathrm{C}_{3}$ and the stable $\mathrm{Ti}(\mathrm{C}, \mathrm{N})$ particles fairly evenly scattered through the material. Tian et al. (2003b) also found experimentally that in the range of deformation temperatures of $1000-1050{ }^{\circ} \mathrm{C}$, both $\mathrm{MC}$ and $\mathrm{M}_{7} \mathrm{C}_{3}$ can be present. Table 1 provide summarized information reported in literature about the crystal structure and solvus temperature for the precipitates and carbides reported in literature for Nimonic $80 a$

In this paper, the forgeability of Nimonic 80a was studied in order to explore the applicability of this alloy to be hot forged in non-isothermal conditions of screw press. Double truncated cones (DTC) of $\varnothing 100 \times 80 \mathrm{~mm}$ dimensions were forged in Schuler AG 2100 tonne screw press at three temperatures, 950, 1050 and $1150{ }^{\circ} \mathrm{C}$, covering the full range of forging temperatures reported for Nimonic 80a (Dieter et al., 2004). Hot forging trials were conducted by applying initial die speeds of $600 \mathrm{~mm} / \mathrm{s}$, representative of industrial conditions. The impact of non-isothermal conditions, forging temperature, strain and strain rate was analysed on the microstructural 
evolution of Nimonic 80a. Another important aspect covered in the present work is the role of soaking treatments in the as-preforged microstructure, in terms of both grain growth processes and dissolution/precipitation of carbides/precipitates, prior to forging operations. Although the analysis of the carbides stability in solution treatments and the related grain growth behaviour is reported in literature (Voice and Faulkner, 1985) (Donachie and Donachie, 2002), there is no information about the impact of starting microstructure, prior to forging (aspreforged condition), on the subsequent microstructural evolution of Nimonic 80a during hot forging. For the present work, a direct comparison among the solution treated and the as-forged microstructures was carried out, resulting to be key to fully understand both the recrystallization behaviour and the microstructural evolution of Nimonic 80a. In addition, the recrystallization mechanisms which operate in Nimonic 80a during hot forging were also analysed.

\section{MATERIAL AND EXPERIMENTAL METHODS}

\subsection{Material}

Nimonic 80A bar of $101.6 \mathrm{~mm}$ in diameter was supplied in the as-solution treated condition. The standard solution annealing treatment for Nimonic 80 a consists into heating up at $1080{ }^{\circ} \mathrm{C}$ during 8 hours, cooling in air to room temperature. The chemical composition is shown in Table 2. From this bar, double truncated cones (DTC) of $\varnothing 100$ $\times 80 \mathrm{~mm}$ dimensions were machined.

\subsection{Hot forging trials}

It is reported that the forging/working temperature for Nimonic 80 a ranges between $950-1150{ }^{\circ} \mathrm{C}$ (Dieter et al., 2004). Temperatures higher than $1150{ }^{\circ} \mathrm{C}$ could provoke incipient melting, especially under high strain rates (adiabatic heating). Based on these finding, three forging temperatures, 950, 1050 and $1150^{\circ} \mathrm{C}$, were selected in order to analyse the impact of non-isothermal conditions on the microstructural evolution of Nimonic 80a, covering the full range of forging temperatures. The hot forging trials of DTCs were carried out in the screw press (Schuler AG 2100 tonne) located at the Advanced Forming Research Centre (AFRC, Glasgow) with die temperatures of $250^{\circ} \mathrm{C}$. The preheating/soaking of DTCs by isothermal holding during 1 hour prior to forging was performed in a rotary furnace (Electrotherm 5700) attached to the screw press. Height reduction slightly above $50 \%$ was obtained (52-55\%) in one single blow for the three DTCs. After the hot forging operations, the DTCs were cooled in air. 


\subsection{FEM simulation}

FEM simulations were run in DEFORM software by using flow stresses data published by Srinivasa and Prasad (1995) for the three selected temperatures, and considering the chilling effect of the dies at $250^{\circ} \mathrm{C}$. Figure 1 shows the temperature, strain and strain rate distribution across a DTC section in the course of the upsetting process at $1150^{\circ} \mathrm{C}$. As deformation proceeds, there is a gradual increase of strain across the DTC, reaching peak values of both temperature (adiabatic heating) and strain for the target $50 \%$ of reduction $(H=40 \mathrm{~mm})$. Figure 1 . a \& b depict the temperature and strain distribution, respectively, at this stage $(H=40 \mathrm{~mm})$. On the other hand, the strain rate increases during the early stages of deformation, but it decreases after reaching the maximum values for a reduction of about $38 \%(H \approx 50 \mathrm{~mm})$. Figure $1 . \mathrm{c}$ plots the strain rate distribution at this point $(H \approx 50 \mathrm{~mm})$ when maximum strain rate values are achieved. In a similar fashion, temperature, strain and strain distribution in DTCS forged at lower temperatures $\left(1050\right.$ and $\left.950{ }^{\circ} \mathrm{C}\right)$ will be also represented for final thickness of 40 and $50 \mathrm{~mm}$. As shown in Figure 1, the distribution of deformation parameters is not uniform, denoting the formation of the characteristic gradient pattern ("X"). The non-uniform distribution of deformation parameters is due to both the formation of dead zones (friction with the dies), and the chilling effect of the cold dies. The regions near the contact surfaces, especially those areas close to the bottom die (higher chilling effect), show large areas with a significant drop in temperature and lower values of both strain and strain rate distribution. The highest values of deformation parameters are found in the centre of the DTC, but also inside the X pattern.

In order to understand the impact of both forging temperature $\left(950,1050\right.$ and $\left.1150{ }^{\circ} \mathrm{C}\right)$ and deformation parameters (strain and strain rate) on microstructural evolution on Nimonic 80a, 9 regions distributed across the thickness (top, centre, and bottom) were considered for microstructural analysis (see Figure 1). These 9 regions basically cover most of the deformation gradients found in the DTCs, such as the regions of maximum and minimum deformation (dead zones), and the chilling effect of dies. Finally, Table 3 summarises the effective strain and strain rate values for the 9 selected regions for the three forging temperatures, estimated from the FEM simulations

\subsection{Microstructural analysis}

The occurrence and evolution of dynamic recrystallization (DRX) or dynamic recovery (DRV) are influenced by many factors, such as deformation temperature, strain rate, degree of deformation but also by the initial microstructure (Dieter et al., 2004). In the present work, the microstructure in the as-received (solution annealed) and the as-preheated condition, prior to hot forging, was analysed. Four samples were sectioned for 
microstructural observations at $1 / 4$ thickness position of the original bar diameter and along the rolling direction. For the metallurgical analysis of pre-forged microstructure, three samples were heat treated (isothermal holding) during 1 hour at 950,1050 and $1150^{\circ} \mathrm{C}$, respectively, followed by water quenching. The main aim was to simulate the soaking/preheating treatment of DTCs prior to forging, and to avoid any potential precipitation during cooling to room temperature.

For the metallurgical analysis in the as-forged condition, sections from DTCs were cut by Electron Discharging Machining (EDM). The surface for metallurgical analysis were prepared by conventional grinding and polishing techniques. The microstructure of Nimonic 80a was revealed by etching with $15 \mathrm{~mL} \mathrm{HCl}+10 \mathrm{~mL}$ acetic acid +5 mL HNO3 + 2 drops glycerol. Optical micrographs were taken from the 9 selected regions (Figure 1 ) in order to analyse different microstructural aspects, such as grain size distributions, recrystallization mechanisms and carbides dissolution/precipitation. In addition, scanning electron microscopy (SEM) was used to analyse in more detail the precipitation observed in grain boundaries and to confirm the presence of both unrecrystallized grains and twin boundaries in new DRX grains, not detected by conventional optical microscopy.

\section{RESULTS}

Microstructural analysis was conducted in the as-received and the as-preheated conditions to analyse the influence of initial microstructure on the microstructural evolution of Nimonic 80a, see section 3.1. The impact of forging temperature, strain and strain rate in the as-forged condition (DTCs) is described in the 3.2 section.

\subsection{As-received and preforged microstructure}

The microstructure in the as-received condition is characterized by a homogeneous grain size distribution (Figure 2.a) and the presence carbides on both grain boundaries and in the interior of the $\gamma$-matrix (Figure 2.b).

Figure 3 depicts optical micrographs for the as-preforged microstructure. It is evident that a remarkable grain growth takes place at the highest temperature $\left(1150^{\circ} \mathrm{C}\right)$. An average grain size of $274 \pm 60 \mu \mathrm{m}$ was found for the preheated sample at $1150{ }^{\circ} \mathrm{C}$. This figure is between 4 and 5 times larger than the average grain size in the asreceived $(50 \pm 49 \mu \mathrm{m})$ and the as-preforged condition: $50 \pm 49$ and $71 \pm 46 \mu \mathrm{m}$ for 950 ad $1050{ }^{\circ} \mathrm{C}$, respectively.

The impact of preheating treatment, prior to hot forging operations, on the occurrence of dissolution and/or precipitation of carbides was analysed. Figure 4 analyses the types of carbides found in the $\gamma$-matrix in the asreceived condition (solution annealing). Two main types of carbides were identified. One consists of irregular shaped carbides of large size distributed irregularly in the $\gamma$-matrix (see Figure 4.a). As shown in Figure 4.d \& e, 
they are Ti-rich carbides ( $\mathrm{TiC}$ ), presenting a core in the interior which seems to be $\mathrm{Al} \mathrm{Mg-rich} \mathrm{oxides.} \mathrm{It} \mathrm{is} \mathrm{assumed}$ that the TiC carbides nucleate at these oxides at high temperatures. Another type of carbides are $\mathrm{Cr}$-rich carbides with variables sizes and morphologies (round, elongated) as shown in Figure 4.b \& c. They are identified, based on both the chemical composition (Figure 4.f) and reported literature, as $\mathrm{M}_{7} \mathrm{C}_{3}$-type carbides. They were found in grain boundaries and in the interior of the $\gamma$-matrix.

A direct comparison of the carbides distribution among the pre-forged samples at the three forging temperatures is shown in Figure 5:

- At $950{ }^{\circ} \mathrm{C}$, a remarkable precipitation (continuous films) of $\gamma^{\prime}$ precipitates decorate all the grain boundaries, with the exception of twin boundaries, where only discrete distribution of precipitates were observed. In addition, massive precipitation in what seems to be migrating boundaries was found (Figure 5.a). Note that the samples were water quenched after isothermal holding during 1 hour. Therefore, it is assumed that such precipitation took place during the isothermal holding treatment at $950{ }^{\circ} \mathrm{C}$.

- At $1050{ }^{\circ} \mathrm{C}$, no significant differences were observed in direct comparison to the as-received condition, in terms of the type and distribution of carbides. In this case, no grain boundary precipitation was found (Figure 5.b).

- At $1150{ }^{\circ} \mathrm{C}$, it is evident the dissolution of a high proportion of the irregular shaped particles, identified as $\mathrm{Cr}_{7} \mathrm{C}_{3}$ carbides (Figure 5.C). However, this is not the case for the large Ti-rich carbides (TiC), mostly located in the interior of the coarse grains.

\subsection{As-forged microstructure}

\subsubsection{DTC forged at $1150^{\circ} \mathrm{C}$}

Optical micrographs of the 9 selected regions from DTC forged at the highest temperature $\left(1150{ }^{\circ} \mathrm{C}\right)$ are plotted in Figure 6. Points 1 and 2 , which correspond to regions with the highest levels of deformation $\left(\varepsilon_{\mathrm{P} 1} \approx 1.8 ; \varepsilon_{\mathrm{P} 2} \approx\right.$ 0.7), develop fully recrystallized structures with homogeneous grain size distributions. In contrast, Point 3 presents a duplex structure characterized by a combination of coarse elongated grains (unrecrystallized grains) partially consumed/surrounded by recrystallized grains (equiaxed grains with annealing twins). The duplex structure of region 3 is similar to those found at top positions (P4, PA and P5), despite of the large differences in strain $\left(\varepsilon \mathrm{P} 3 \approx 0.3, \varepsilon \mathrm{P} 4 \approx 0.1, \varepsilon \mathrm{PA} \approx 0.8\right.$ and $\left.\varepsilon_{\mathrm{P} 5} \approx 0.4\right)$ and strain rate $\left(\dot{\varepsilon}_{P 3} \approx 4 \mathrm{~s}^{-1}, \dot{\varepsilon}_{P 4} \approx 2 \mathrm{~s}^{-1}, \dot{\varepsilon}_{P A} \approx 3 \mathrm{~s}^{-1}, \dot{\varepsilon}_{P 5} \approx 30 \mathrm{~s}^{-1}\right)$. 
Based on these latter results, it seems that the chilling effect of the top die is not affecting the microstructure evolution of Nimonic 80a in a significant manner. Other aspects such as adiabatic heating could be playing a more important role. Considering that the strain level of PA region ( $\varepsilon \mathrm{PA} \approx 0.8)$ is similar to that for $\mathrm{P} 2(\varepsilon \mathrm{P} 2 \approx 0.7)$, the only significant difference between both regions is the temperature increase as a result of the adiabatic heating. It seems that an equivalent strain as low as 0.1 (region P4) at $1150^{\circ} \mathrm{C}$ satisfies the conditions for the occurrence of recrystallization processes, but instead, an equivalent strain as high as 0.8 (region PA) it is not high enough to fully replace the deformed structure.

At positions in contact with the bottom die (P76, PB, P7), fully and highly unrecrystallized structures were found. Regions P7 (Figure 6.j) and PB (Figure 6.k) depict a so-called necklace structure with fine DRX grains nucleated on grain boundaries. For region P6 (Figure 6.I), in contrast, a fully unrecrystallized structure is observed with no sign of any recrystallization process. These results are in good agreement with the stronger chilling effect of the bottom die. Based on the microstructural analysis, no significant differences associated to strain rate were detected. When comparing regions with similar strain level but with large differences in strain rate (P1 vs. P2, PA vs. P5 and PB vs. P7) very similar grain size distributions were found. Based on these results, it seems that strain rate does not play a significant role on microstructural evolution for Nimonic 80 a forged at $1150{ }^{\circ} \mathrm{C}$ under nonisothermal conditions. Other aspects, such chilling effect at the bottom die, primarily, and adiabatic heating present a far stronger impact on Nimonic 80a at this temperature. However, no evidences of shear bands formation or strain localisation were observed in any of the regions analysed across the DTC forged at $1150{ }^{\circ} \mathrm{C}$.

Figure 7 shows SEM pictures taken at regions with different fractions of recrystallized/unrecrystallized structures $(P 4, P 6)$ in direct comparison to the preforged microstructure. In those regions fully recrystallized (Figure 7.b), continuous chains of precipitates decorating grain boundaries can be observed, with the exception of the twin boundaries which are free of precipitates. In contrast, in those regions with partial or no recrystallization (Figure 7.c), the same chain of precipitates can be detected not only in the grain boundaries of unrecrystallized grains, but also on the deformed twin boundaries. The presence of continuous chains of precipitates on grain boundaries in the as-forged condition, no previously observed in the as-preforged structure (Figure 7.a), clearly indicates that such precipitation took place after hot forging, probably during air cooling to room temperature. From Figure 7.b \& $c$, the identification of the recrystallized grains can be easily done by SEM, by the presence of annealing twin boundaries and the differences in contrast of unrecrystallized/deformed grains, denoting internal strain distribution. This latter one confirms that the large grain sizes observed in those regions with duplex structure are, in fact, unrecrystallized grains, dismissing therefore, mechanisms such as abnormal grain growth. 


\subsubsection{DTC forged at $1050^{\circ} \mathrm{C}$}

Figure 8 shows the optical micrographs of the 9 selected regions of the DTC forged at $1050{ }^{\circ} \mathrm{C}$. Similarities in the recrystallization behaviour were found between both DTCs forged at 1150 and $1050{ }^{\circ} \mathrm{C}$. At the centre positions, regions 1 and 2 , with the highest levels of deformation $\left(\varepsilon p_{1} \approx 1.8 ; \varepsilon p_{2} \approx 0.7\right)$, also developed fully recrystallized structures, no finding significant differences in the grain size distributions despite the large differences in strain and strain rate between both regions $\left(\dot{\varepsilon}_{P 1} \approx 30 \mathrm{~s}^{-1}, \dot{\varepsilon}_{P 2} \approx 10 \mathrm{~s}^{-1}\right)$.

The region 3 (Figure 8.g), again, presents a partially recrystallized structure, similar to those found at top positions (P4, PA and P5) regardless the differences in strain $\left(\varepsilon \mathrm{P}_{4} \approx 0.1, \varepsilon \mathrm{PA} \approx 0.8\right.$ and $\left.\varepsilon \mathrm{P} 5 \approx 0.4\right)$ and strain rate $\left(\dot{\varepsilon}_{P 4} \approx 2 \mathrm{~s}^{-1}\right.$, $\left.\dot{\varepsilon}_{P A} \approx 3 \mathrm{~s}^{-1}, \dot{\varepsilon}_{P 5} \approx 30 \mathrm{~s}^{-1}\right)$. At $1050^{\circ} \mathrm{C}$, the unrecrystallized grains are much finer than those observed at $1150{ }^{\circ} \mathrm{C}$, and they represent smaller area fractions. At bottom positions (P6, PB, P7), fully and highly unrecrystallized structures are also developed due to, mainly, the strong chilling effect of the bottom die. The regions P7 (Figure 8.j) and PB (Figure 8.k) depict necklace structures with DRX grains nucleated on old grain boundaries. Again, no evidences of shear bands formation or strain localisation were observed.

Figure 9 shows SEM pictures taken at regions with fully recrystallized (P1) and unrecrystallized (P6) structures, in direct comparison to the as-preforged condition $\left(1050{ }^{\circ} \mathrm{C}-1\right.$ hour). In terms of carbides precipitation, no significant differences among regions with fully recrystallized (P1, Figure 9.b) and un-recrystallization structures (P6, Figure 9.c) were observed. In all the cases, discrete and chains of precipitates were found at grain boundaries, with the only exception of the annealing twin boundaries, which remain free of precipitates.

\subsubsection{DTC forged at $950^{\circ} \mathrm{C}$}

Optical micrographs of the 9 selected regions of the DTC forged at $950{ }^{\circ} \mathrm{C}$ are shown in Figure 10 . With the exception of regions $\mathrm{P} 1$ and $\mathrm{P} 2$, above $90 \%$ of the area fraction of the DTC, regardless the amount of deformation, strain rate and position (top, centre, bottom), present fully unrecrystallized structures, no showing any evidence of nucleation of new grains on either grain boundaries or in the interior of grains.

Region P1 is the only region which developed a fully recrystallized structure (Figure 10.i), presenting the smallest grain size across the DTCs forged at the three temperatures. This fully recrystallized region corresponds to a very narrow area whose centre is located at $3 \mathrm{~mm}$ above the geometrical centre of the DTC, denoting inhomogeneous deformation across the thickness. This microstructure seems to be strongly associated to the highest levels of deformation parameters $\left(\varepsilon_{P 1} \approx 2, \dot{\varepsilon}_{P 1} \approx 30 \mathrm{~s}^{-1}\right)$, but mainly to the remarkable adiabatic heating effect, by increasing the temperature up to $1080{ }^{\circ} \mathrm{C}$ in this region (see Figure 10.a). In contrast, region P2 shows a necklace structure 
with a large fraction of unrecrystallized grains (Figure 10.h), despite of the significant level of deformation ( $\varepsilon_{P 2} \approx$ 0.7) and adiabatic heating effect, increasing the temperature in the range $980-1030{ }^{\circ} \mathrm{C}$. Even at this low forging temperature, no evidences of shear bands formation or strain localisation were found.

Figure 11 shows SEM micrographs taken in the regions with fully and partially recrystallized structures (P1 and $\mathrm{P} 2$, respectively), in direct comparison to the as-preforged condition ( $950{ }^{\circ} \mathrm{C}-1$ hour). In the as-preforged condition, a remarkable precipitation on the grain boundaries were observed (see Figure 11.a). In the fully recrystallized region (P1, Figure 11.b) only discrete films of precipitates on grains boundaries (not observed in twin boundaries) were found. However, for the region 2 with a partially recrystallized structure (Figure 11.c) films/chains of precipitates, similar to those observed in the as-preforged condition (Figure 11.a), were also found decorating the grain boundaries.

\subsection{Mechanisms of recrystallization}

Additional microstructural analysis were conducted in order to analyse the recrystallization mechanisms which operate in Nimonic 80a during hot forging in screw press. In this sense, Figure 12 shows the microstructure of the region $\mathrm{PB}$ from the $\mathrm{DTC}$ forged at $1150^{\circ} \mathrm{C}$. This area corresponds to a region with a high level of deformation $(\varepsilon$ $\approx 0.6$ ). Because of chilling effect of the bottom die, a significant drop of both temperature and strain takes place allowing to observe the recrystallization behaviour of Nimonic 80A at early stages. New DRX grains nucleate almost exclusively at deformed grain boundaries, including twin boundaries, developing the so-called necklace structure, characteristic of discontinuous dynamic recrystallization (DDRX) (Humphreys and Hatherly, 2004), (Thomas et al., 2009).

Figure 13 also shows partially recrystallized structures of Nimonic 80a located close to the region 6 of the DTC forged at $1150{ }^{\circ} \mathrm{C}$ by means of SEM microscopy. From both micrographs, it is evident the presence of a large fraction of twin boundaries within the new DRX grains, denoting the key role of twin boundaries formation on the recrystallization behaviour of Nimonic 80a.

At lower forging temperatures, Figure 14 and Figure 15 depict the partially recrystallized microstructures of the regions PB and 2 from DTCs forged at 1050 and $950{ }^{\circ} \mathrm{C}$, respectively. From these pictures, it is evident the presence of new DRX grains nucleated in the old grain boundaries. However, at $950^{\circ} \mathrm{C}$, the presence of bulging and necklace structure is not as evident by optical microscopy, or at least as much, as it is at higher temperatures (DTC 1150 ${ }^{\circ} \mathrm{C}$, Figure 12). 
In order to shed more light on this aspect, further analysis by using SEM were carried out. Figure 16 shows SEM micrographs of regions with partial recrystallization from the DTCs forged at 1050 and $950{ }^{\circ} \mathrm{C}$, respectively, showing the formation of bulges at serrated grain boundaries (Figure 16.a) and large fraction of annealing twin boundaries in the interior of the new grains (Figure 16.b).

Evidences of other recrystallization mechanisms, different from DDRX, which are operating in Nimonic 80a during hot forging in screw press were found. Figure 17 shows again the microstructure of the region PB from the double cone forged at $1150{ }^{\circ} \mathrm{C}$. In Figure $17 . \mathrm{a}$, it is possible to see the transition from fully recrystallized structure (top image) to necklace structure (bottom image) due to the chilling effect of the bottom tool. At higher magnifications, a careful examination of Figure 17.b reveals not only the presence of grain boundaries free of recrystallized grains, but also the formation of new grains inside the initial grains (coarse unrecrystallized grains). This latter one is even more evident in Figure 17.c, where clusters of new grains can be clearly detected in the grain interior. Finally, Figure 17.d shows what it seems to be the nucleation of new grains on second-phase particles (carbides).

The nucleation of new DRX grains on carbides located in the interior of deformed grains were also observed in the DTC forged at the lowest temperature $\left(950^{\circ} \mathrm{C}\right)$, see Figure 18 . Based on microstructural observations across the three forging temperatures, a significant fraction of new recrystallized grains located in the interior of deformed grains present carbides in the grain boundaries and/or in their interior.

\section{DISCUSSION}

\subsection{Microstructural analysis in the as-received and preforged condition}

The microstructural analysis of Nimonic 80a in as-received condition (solution annealed) reveals a homogeneous grain size distribution and the presence carbides on both grain boundaries and $\gamma$-matrix (Figure 2). Those carbides located within the grains ( $\gamma$-matrix) form clearly a pattern, which corresponds apparently to carbides precipitated on prior grain boundaries. For nickel-base superalloys, it is reported that grain growth takes place during solution annealing treatments (Donachie and Donachie, 2002). Therefore, it is assumed that grain boundary migration during grain growth left behind the carbides in the course of solution annealing treatments.

Dislocations and grain boundaries are known to present heterogeneous nucleation sits for carbides, and different diffusion velocities at grain boundaries or along dislocation lines, as compared to bulk diffusion, influencing their growth rates (Tian et al., 2003b). In the course of solution annealing treatments, $\mathrm{Cr}_{7} \mathrm{C}_{3}$ carbides can precipitate 
heterogeneously in grain boundaries (Voice and Falukner, 1985). Due to the high diffusion velocity of grain boundaries, these carbides increase their size. The coarsening of pinning particles is accompanied by a reduction of the pinning force. As a consequent, grain boundaries with enough energy and mobility migrate (grain growth), leaving behind the coarse particles ( $\mathrm{Cr}_{7} \mathrm{C}_{3}$ carbides). The thermal stability of $\mathrm{Cr}_{7} \mathrm{C}_{3}$ carbides at $1080{ }^{\circ} \mathrm{C}$ (Voice and Falukner, 1985) can explain the no dissolution of such particles for Nimonic 80a in the as-received condition, after the solution annealing treatment.

In the as-preforged condition at $1150^{\circ} \mathrm{C}$, the dissolution of a high proportion of the irregular shaped particles, identified as $\mathrm{Cr}_{7} \mathrm{C}_{3}$ carbides (Figure 5.c), is accompanied by a remarkable grain growth in direct comparison with the samples preheated at 950 and $1050{ }^{\circ} \mathrm{C}$. These results also confirm the role of irregular shaped particles $\left(\mathrm{Cr}_{7} \mathrm{C}_{3}\right.$ carbides) on grain size control, restricting the grain growth during preheating, prior to hot forging. Concerning the $\mathrm{MC}$ carbides $(\mathrm{TiC})$, due to its large size and small number, they are not expected to play significant role on grain growth control. Note that most of them are located in the interior of grains. Apparently, the size and morphology of these primary carbides does not change after the soaking treatment at temperatures as high as $1150^{\circ} \mathrm{C}$ (Figure 5.a), in agreement with the reported thermal stability of these carbides (Voice and Falukner, 1985).

\subsection{Microstructural analysis in the as-forged condition}

The superalloys derive their strength mostly from solid-solution hardeners and precipitated phases. Principal strengthening precipitate phases are $\gamma^{\prime}$ and $\gamma^{\prime \prime}$, which are found in iron-nickel- and nickel-base superalloys. Carbides may provide limited strengthening directly (e.g., through dispersion hardening) or, more commonly, indirectly, e.g., by stabilizing grain boundaries. However the presence of precipitates/carbides in the as-preforged condition not only can play a very important role on the grain growth behaviour, as discussed previously, but also on the recrystallization mechanisms that control the microstructural evolution.

Duplex structures characterized by a combination of coarse elongated grains (unrecrystallized grains) partially consumed/surrounded by recrystallized grains were found in the DTC forged at $1150{ }^{\circ} \mathrm{C}$, for the regions P3, P4, PA and P5 in particular (see Figure 6). At $1050^{\circ} \mathrm{C}$, the unrecrystallized grains (for the same positions) are much finer than those observed at $1150{ }^{\circ} \mathrm{C}$, and they represent smaller area fractions (see Figure 8). Such differences can be explained by the prior microstructure in the as-preforged condition, in which the soaking treatment at $1050{ }^{\circ} \mathrm{C}$ did not provoke a significant grain growth prior to forging (Figure 3.a). Grain boundaries are favoured nucleation sites, and therefore the number of available nucleation sites is greater for a fine-grained material, accelerating the recrystallization kinetics (Humphreys and Hatherly, 2004). In addition, the stored energy of a 
metal deformed to low strains $(\varepsilon<0.5)$ tends to increase with a decrease in grain size increasing therefore the driving force for recrystallization (Humphreys and Hatherly, 2004). For these reasons, a fine-grained material is expected to recrystallize more rapidly than a coarse-grained material.

No microstructural defects or cracks associated to both adiabatic heating and localised deformation were found in any of the DTCs analysed in the present work. These results are in contrast with those reported by Salehi et al. (2015) who reported the formation shear bands during hot compression tests for Nimonic 80a. Such discrepancies could be explained by the significant differences in the experimental procedure employed between both works. These authors conducted compression tests at high temperature $\left(1175^{\circ} \mathrm{C}\right)$ with much smaller workpieces (compression samples) and employing cold dies (room temperature), resulting in conditions not representative of screw press for hot forging at industrial scale.

Despite the no presence of defects or crack, the non-isothermal conditions of screw press resulted into the development of heterogeneous structures across the thickness for the DTCs forged at 1050 and $1150{ }^{\circ} \mathrm{C}$. The chilling effect of the bottom die, strongly affected the recrystallization behaviour of Nimonic 80a. Large fraction of unrecrystallized structures were found for DTC forged at $1050{ }^{\circ} \mathrm{C}$ (Figure 8) and $1150{ }^{\circ} \mathrm{C}$ (Figure 6), in those regions localized close to the bottom die (P7, PB, P6).

At $950{ }^{\circ} \mathrm{C}$ (see Figure 10), by contrast, no apparent differences were found among those regions located at top (P5, PA, P4) and bottom positions (P7, PB, P6), not being affected by the non-isothermal and inhomogeneous strain distribution across the thickness of the DTC. Fully unrecrystallized structures were found in all the regions with the exception of Positions 1 and 2, which developed fully and partially recrystallized structures, respectively (see Figure 10). From the microstructural analysis in the as-preforged condition at $950{ }^{\circ} \mathrm{C}$, a remarkable amount of precipitates decorating all the grain boundaries were observed, see Figure 11.a. It is reported that the occurrence and development of DRX during hot deformation in Nimonic 80A alloy could be strongly retarded/hindered by the presence of continuous carbides/precipitates chains/films on grain boundaries before hot forging (Donachie and Donachie, 2002). However, it seems that the remarkable adiabatic heating effect in region 1 provided enough energy to enhance the grain boundary mobility, allowing to initiate and complete fully the recrystallization. In this region, as shown in Figure 11.b, discrete films of precipitates on recrystallized grains boundaries (not observed in twin boundaries) were detected. This latter observation could be explain by the dissolution of precipitates previously formed in old grain boundaries, as new grain boundaries migrate and recrystallization proceeds, leaving behind the precipitates. During cooling, discrete precipitates re-precipitate on 
new grain boundaries, in a similar fashion as observed in the DTC forged at $1050^{\circ} \mathrm{C}$ (Figure 9). On the other hand, the deformation parameters of region $2, \varepsilon \mathrm{P} 2 \approx 0.7$ and $\dot{\varepsilon}_{P 2} \approx 10 \mathrm{~s}^{-1}$, satisfy the conditions for the nucleation of new DRX grains (see Figure 10.h). The Figure 11.c confirms the nucleation of new DRX grains in grain boundaries decorated with chains of precipitates for the region 2. Based on these results, it seems that occurrence of DRX is not hindered by the presence of such precipitates, being the mobility of the new boundaries (growth of new DRX grains) the main limitation to generate a new grained structure. The presence of large fractions of unrecrystallized structures clearly indicates that the deformation temperature of $950{ }^{\circ} \mathrm{C}$ resulted to be too low to hot forge Nimonic 80a in screw press.

\subsection{Mechanisms of recrystallization}

Basically, there are two types of nucleation mechanisms reported to operating in the new grain development during DRX, i.e. discontinuous DRX (DDRX) and continuous DRX (CDRX) (Humphreys and Hatherly, 2004), (Thomas et al., 2009). The main characteristic of DDRX is the nucleation of new DRX grains by grain boundary bulging following by growth (Yanushkevich et al., 2015). By contrast, CDRX generally involves the formation of arrays of low angle boundaries and a gradual increase in the boundary misorientations through accumulation and rearrangement of the dislocations during deformation (Wang et al., 2008), (Gourdet and Montheillet, 2000).

In the present work, characteristic necklace structures with the formation of new DRX grains on old grain boundaries were observed for Nimonic 80a, see Figure 12.a. However, some grain boundaries remain free of DRX grains (Figure 12.b). In this sense, Tian et al. (2004) studied the dynamic recrystallization and dynamic recovery in hot deformed nickel-based superalloy. He also observed that DRX grain nucleates at grain boundaries, starting with bulging of grain boundaries and some of the GB's remain always free of DRX grains in spite of very large deformation. They found higher dislocation density at GBs, associated to inhomogeneous distribution of dislocations. The author pointed out that the inhomogeneity of dislocation distributions can be due to different grain compatibility between neighbouring grains, pile-ups of dislocations or hindrance to dislocation motion at GBs or other obstacles. The nucleation probabilities of DRX are drastically influenced by both, distribution of dislocations and a strong gradient of orientation between two neighbouring grains, identifying this later factor as the main reason to explain the occurrence of DRX at some grain boundaries.

Another aspect about the recrystallization behaviour of Nimonic 80a can be seen in Figure 12.b. The nucleation of new DRX grains also take place in twin boundaries of deformed grains. During hot deformation, the pre-existing twin boundaries, characterized by $60^{\circ}$ rotation around the $<111>$ axis, rotate away from their original $\Sigma 3$ 
coincidence site lattice orientation relationship, converting into serrated high-angle boundaries during the deformation process as reported by both Thomas et al. $(2004,2009)$ and Jorge-Badiola et al. $(2005)$. In this sense, Shi et al. (2013) studied by EBSD the twin character evolution during hot forging of Nimonic 80a in response to deformation at $1150{ }^{\circ} \mathrm{C}$ with a strain of 0.1 . He found that many original coherent twin boundaries transformed into boundaries composed of coherent twin boundaries and incoherent twin boundaries or even random high angle boundary.

Concerning twin boundaries but in the interior of new DRX grains, it is reported that twinning occurs in the early stages of recrystallization, creating the required mobile high angle boundary needed for recrystallization (Humphreys and Hatherly, 2004). Such twin boundaries, commonly close the protuberances, are formed by bulging which effectively isolates the nuclei. Continuing deformation disorients twin boundaries into ordinary mobile grain boundaries (Thomas et al., 2009). This is in good agreement with the significant bulging and the large fraction of twin boundaries within the new DRX grains observed in partially recrystallized structures of the DTC forged at $1150{ }^{\circ} \mathrm{C}$ (Figure 13).

In the present work, Nimonic 80a was hot forged at three temperatures covering the full range of forging temperatures reported for this alloy (Dieter et al., 2004). It is reported that the mechanism of recrystallization at low temperatures can change, where the dynamic development of new grains at relatively temperature is not associated to grain boundary migration as it does for DDRX (Doherty et al., 1997). Different mechanisms are proposed to explain the formation high angle boundary during continuous recrystallization (CDRX) (Thomas, et al., 2009). (Belyakov et al., 2012). However, at lower forging temperatures, 1050 and $950{ }^{\circ} \mathrm{C}$, see Figure 16, both the formation of bulges at serrated grain boundaries (Figure 16.a) and the presence of large fractions of annealing twin boundaries in the interior of new DRX grains (Figure 16.b) were found. This latter one implies grain boundary migration and therefore, no change in recrystallization mechanism/s at lower temperatures for Nimonic 80a. These findings clearly indicate that DDRX is the main recrystallization mechanism for Nimonic 80a and operates at deformation temperatures as low as $950^{\circ} \mathrm{C}$ under screw press conditions and for the range of strain and strain rates covered across the employed DTCs.

Evidences that other recrystallization mechanisms, different from DDRX, are operative during hot forging of Nimonic 80a were found. The nucleation of new grains on second-phase particles (carbides) was observed across the three forging temperatures $\left(950,1050\right.$ and $1150^{\circ} \mathrm{C}$ ), as shown in Figure 17 and Figure 18. These observations are consistent with the particle-stimulated nucleation mechanism (PSN) (Doherty et al., 1997). The PSN increase 
the density of sites at which recrystallization can be initiated and therefore the overall recrystallization kinetics. The presence of clusters of new grains indicates that the new PSN grains promote the formation of new recrystallized grains in the interior of deformed grains by providing new nucleation sites for further recrystallization.

\section{CONCLUSIONS}

- No evidences of shear bands or flow/strain localisation associated to adiabatic heating was found in hot forged DTCs for Nimonic 80a. However, inhomogeneous structures were developed as a result of the non-isothermal conditions of screw press.

- Discontinuous Dynamic Recrystallization (DDRX) was found to be the main recrystallization mechanism which operates in Nimonic 80a in screw press. Particle-stimulation nucleation (PSN) mechanism also operates, as well as DDRX, in the full range of temperatures explored in the present work $(950-1150$ $\left.{ }^{\circ} \mathrm{C}\right)$. No dependency of the recrystallization mechanisms with the forging temperature was found.

- Soaking treatments play a very important role on microstructural evolution during hot forging for Nimonic 80a due to its strong impact on both grain growth and dissolution/precipitation of precipitates/carbides.

- At the highest forging temperature, $1150{ }^{\circ} \mathrm{C}$, duplex structures characterized by a combination of coarse unrecrystallized grains partially consumed/surrounded by recrystallized grains were found. The dissolution of high fractions of chromium carbides which control grain growth during the soaking treatment (as-preforged condition) resulted into coarse preforged structures, reducing dramatically the density of nucleating sites for subsequent recrystallization after hot forging.

- At $1050^{\circ} \mathrm{C}$, the combination of both fine grain size distribution in the as-preforged condition and the high mobility of grain boundaries resulted into large fractions of fully recrystallized structures and homogeneous grain size distributions.

- At the lowest forging temperature $\left(950^{\circ} \mathrm{C}\right.$ ), above $90 \%$ of the area fraction of the DTC presents fully unrecrystallized microstructures. These results clearly denotes that this deformation temperature is too low to hot forged Nimonic 80a in screw press. 


\section{ACKNOWLEDGEMENTS}

The author would like to acknowledge Trevor Barrett (Bifrangi UK Ltd) and the Advanced Forming Research Centre (AFRC) for their support in this project. The author is grateful to Javad Falsafi and Himanshu Lalvani for the help provided for the hot forging simulation of double truncated cones, and Sebastian Nouveau (Aubert \& Duval) for his useful comments and fruitful discussion.

\section{REFERENCES}

Belyakov, A., Dudova, N., Tikhonova, M., Sakai, T., Tsuaki, K., Kaibyshev, R., 2012. Dynamic recrystallization mechanisms operating under different processing conditions. Mater. Sci. Forum 706709, 2704-2709. doi:10.4028/www.scientific.net/MSF.706-709.2704.

Bombac, D., Brojan, M., Tercelj, M., Turk, R., 2009. Response to hot deformation conditions and microstructure development of Nimonic 80A superalloy. Mater. Manuf. Processes 24, 644-648. http://dx.doi.org/10.1080/10426910902769103

Bombac, D., Fazarinc, M., Kugler, G., Spajic, S., 2008. Microstructure development of Nimonic $80 \mathrm{~A}$ superalloy during hot deformation. Mater. Geoenviroment 55(3), 319-328.

Dieter, G.E., Kuhn, H.A., Semiatin, S.L., 2004. Handbook of Workability and Process Design. (2nd ed.) ASM International, USA, pp 57-60.

Doherty, R.D., Hughes, D.A., Humphreys, F.J., Jonas, J.J., Juul Jensen, D., Kassner, M.E., King, W.E., McNelley, T.R., McQueen, H.J., Rollett, A.D., 1997. Current issues in recrystallization: a review. Mater. Sci. Eng., A 238, 219-274.

Donachie, M.J., Donachie, S.J., 2002. Superalloys: A technical guide, second ed. ASM International, pp. 23-39. DOI: 10.1361/stgs2002p025.

Gourdet, S., Montheillet, F., 2000. An experimental study of the recrystallization mechanism during hot deformation of aluminium. Mater. Sci. Eng., A 283, 274-288. https://doi.org/10.1016/S0921-5093(00)00733-4.

Humphreys, F.J., Hatherly, M., 2004. Recrystallization and related annealing phenomena (2nd ed.). Oxford: Elsevier, Oxford, pp 215-266. 
Hwang, S.W., Park, K.T., 2014). Analysis of hot deformation of Nimonic 80a using processing map. Proceedings of the 23th International Conference on Metallurgy and Materials, Brno, Czech Republic.

Jorge-Badiola, D., Iza-Mendia, A., Gutierrez, I., 2005. Study of EBSD of the development of the substructure in a hot deformed 304 stainless steel. Mater. Sci. Eng., A 394, 445-454. https://doi.org/10.1016/j.msea.2004.11.049.

Kim, D.K., Kim, D.Y., Ryu, S.H., Kim, D.J., 2001. Application of nimonic $80 A$ to the hot forging of an exhaust valve head. Mater. Process. Technol. 113, 148-152.

Salehi, M.S., Anjabin, N., Mansoori, R., 2015. Hot deformation behavior of Nimonic 80A superalloy during non-isothermal side pressing. Iranian J. Mater. Forming, 2, 18-29. DOI: 10.22099/IJMF.2015.2912.

Shi, H., 2013. EBSD analysis of twin character evolution during hot deformation in Nimonic 80A (Doctoral dissertation).

Srinivasan, N., Prasad, Y.V.R.K., 1995. Hot working characteristics of nimonic 75, 80A and 90 superalloys: a comparison using processing maps. Mater. Process. Technol. 51, 171-192. https://doi.org/10.1016/0924-0136(94)01602-W.

Thomas, J. P., Bauchet, E., Dumont, C., Montheillet, F., 2004. EBSD investigation and modelling of the microstructural evolution of superalloy 718 during hot deformation. In: Green, K.A., Pollock, T.M., Harada, H., Howson, T.E., Reed, R.C., Schirra, J.J, Walston, S., (Eds.), Proceedings of 10th International Symposium on Superalloys, Champion, USA, pp. 959-968.

Thomas, J.P., Montheillet, F., Semiatin, J.P., 2009. Modelling of Microstructure Evolution during Thermomechanical Processing of Nickel-Base Superalloys. In: D. F. Semiatin (Eds.), ASM Handbook, Fundamentals of Modelling for Metals Processing, vol. 22a, pp. 566-582.

Tian, B., Lind, C., Paris, O., 2003a. Influence of $\mathrm{Cr}_{23} \mathrm{C}_{6}$ carbides on dynamic recrystallization in hot deformed Nimonic 80a alloys. Mater. Sci. Eng., A 358, 44-51. https://doi.org/10.1016/S09215093(03)00329-0.

Tian, B., Lind, C., Schafler, E., Paris, O., 2004. Evolution of microstructures during dynamic recrystallization and dynamic recovery in hot deformed Nimonic 80A. Mater. Sci. Eng., A 367, 198-204. https://doi.org/10.1016/j.msea.2003.10.226.

Tian, B., Zicker, G.A., Lind, C., Paris, O., 2003b. Local microstructure and its influence on precipitation behavior in hot deformed Nimonic 80a. Acta Mater. 51, 4149-4160. https://doi.org/10.1016/S1359-6454(03)00233-7. 
Voice, W.E., Faulkner, R.G., 1985. Carbide stability in Nimonic 80a alloy. Metall. Trans. A 16(4), 511-520.

Wang, Y., Shao, W.Z., Zhen, L., Zhang, X.M., 2008. Microstructure evolution during dynamic recrystallization of hot deformed superalloy 718. Mater. Sci. Eng., A 486, 321-332. https://doi.org/10.1016/i.msea.2007.09.008.

Yanushkevich, Z., Belyakov, A., Kaibyshev, R., 2015. Microstructural evolution of a 304-type austenitic stainless steel during rolling at temperatures of 773-1273K. Acta Mater. 82, 244-254. https://doi.org/10.1016/j.actamat.2014.09.023. 


\section{FIGURE CAPTIONS}

Figure 1. FEM simulation of DTC forged at $1150^{\circ} \mathrm{C}$, identifying the 9 regions of interest considered for microstructural analysis

Figure 2. Optical micrographs of Nimonic 80a in as-received condition (solution annealing)

Figure 3. Optical micrographs of Nimonic 80a preforged samples, heat treated at 950,1050 and $1150{ }^{\circ} \mathrm{C}$ during 1hour followed by water quenching

Figure 4. Type of carbides in Nimonic 80a in as-received condition, Including EDS analysis

Figure 5. Microstructural analysis in the as-preforged condition

Figure 6. Optical micrographs from different regions of DTC forged at $1150{ }^{\circ} \mathrm{C}$ (as-forged condition)

Figure 7. SEM micrographs of as-preforged vs. as-forged condition (DTC forged at $1150^{\circ} \mathrm{C}$ )

Figure 8. Optical micrographs from different regions of DTC forged at $1050^{\circ} \mathrm{C}$ (as-forged condition)

Figure 9. SEM micrographs of as-preforged vs. as-forged condition (DTC forged at $1050{ }^{\circ} \mathrm{C}$ )

Figure 10. Optical micrographs from different regions of DTC forged at $950^{\circ} \mathrm{C}$ (as-forged condition)

Figure 11. SEM micrographs of as-preforged vs. as-forged condition (DTC forged at $950^{\circ} \mathrm{C}$ )

Figure 12. Optical micrographs of Nimonic 80a from the region PB of DTC forged at $1150{ }^{\circ} \mathrm{C}$

Figure 13. SEM micrographs of Nimonic 80a from the region PB of DTC forged at $1150{ }^{\circ} \mathrm{C}$

Figure 14. Region PB - Nimonic 80A DTC forged at $1050^{\circ} \mathrm{C}$

Figure 15. Region 2 - Nimonic 80 a DTC forged at $950{ }^{\circ} \mathrm{C}$

Figure 16. Formation of bulges at serrated grain boundaries, a); and large fraction of twin boundaries on new DRX grains, b).

Figure 17. Grain structures of region PB from DTC forged at $1150^{\circ} \mathrm{C}$

Figure 18. Nucleation of new grains on carbides located in the interior of deformed grains by particle-stimulated nucleation mechanism (PSN) - region 2 of Nimonic 80a DTC forged at $950^{\circ} \mathrm{C}$ 


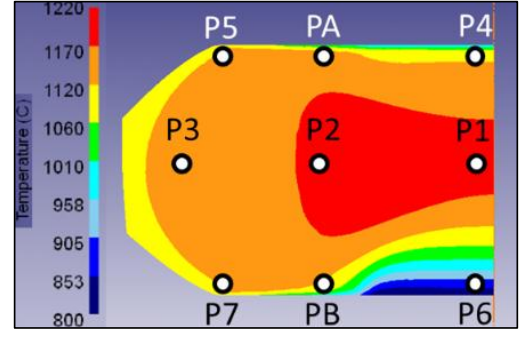

a) Temperature distribution $(H=40 \mathrm{~mm})$

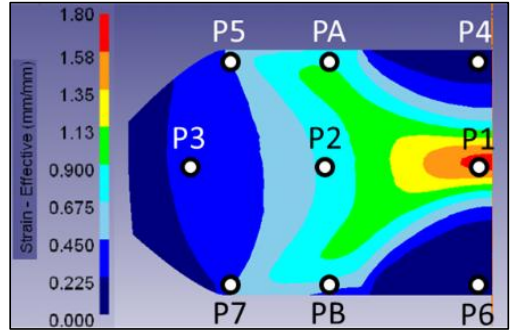

b) Strain distribution $(H=40 \mathrm{~mm})$

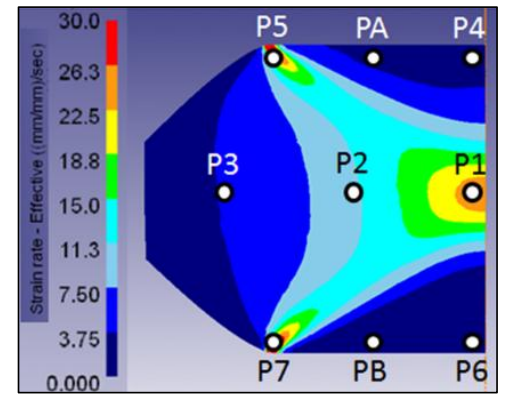

c) Strain rate distribution $(H=50 \mathrm{~mm})$

FIGURE 1. FEM SIMULATION OF DTC FORGED AT $1150^{\circ} \mathrm{C}$, IDENTIFYING THE 9 REGIONS OF INTEREST CONSIDERED FOR MICROSTRUCTURAL ANALYSIS

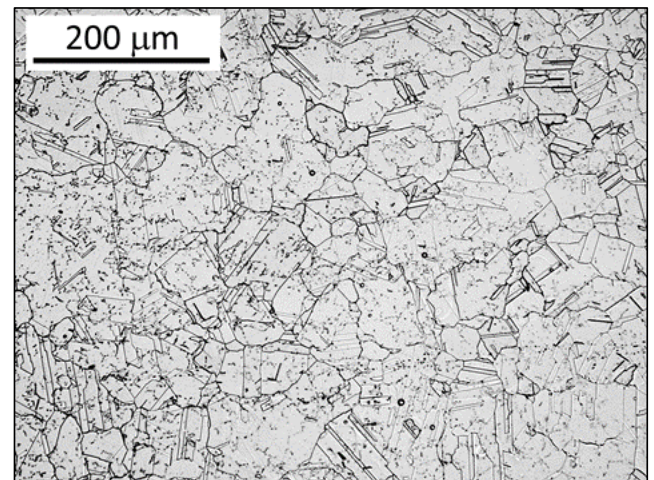

a)

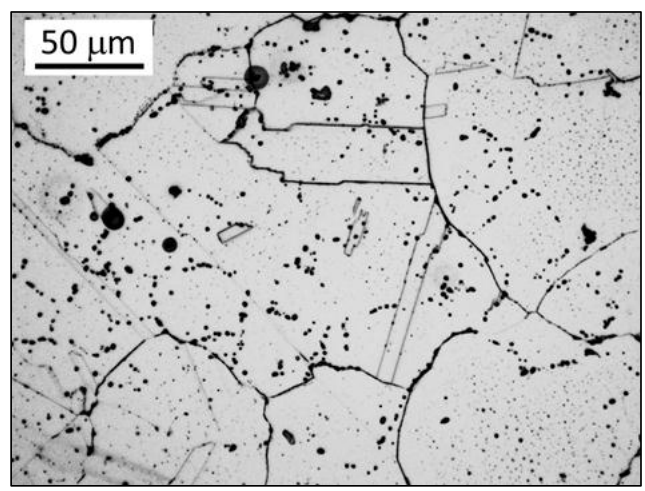

b)

FIGURE 2. OPTICAL MICROGRAPHS OF NIMONIC 8OA IN AS-RECEIVED CONDITION (SOLUTION ANNEALING)

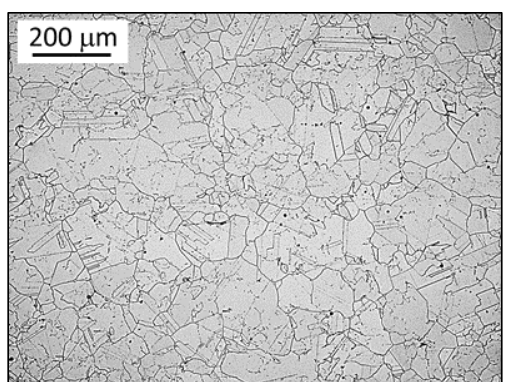

a) $950{ }^{\circ} \mathrm{C}$

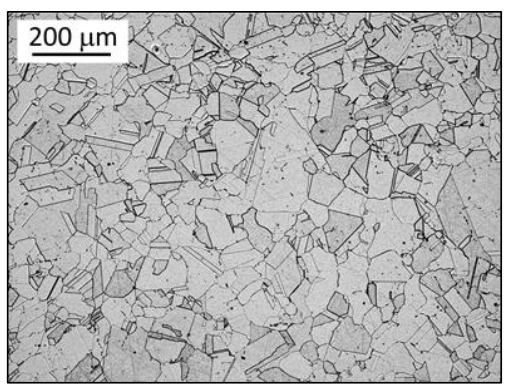

b) $1050{ }^{\circ} \mathrm{C}$

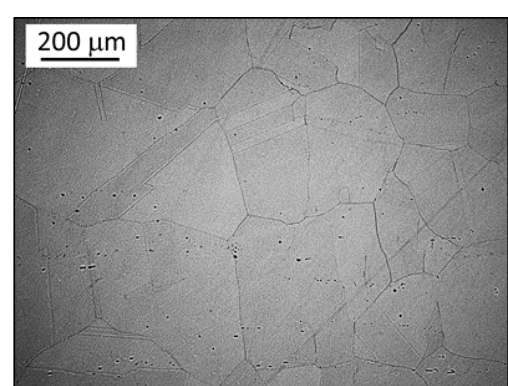

C) $1150{ }^{\circ} \mathrm{C}$

FIGURE 3. OPTICAL MICROGRAPHS OF NIMONIC 80A PREFORGED SAMPLES, HEAT TREATED AT 950, 1050 AND $1150^{\circ} \mathrm{C}$ DURING 1 HOUR FOLLOWED BY WATER QUENCHING 


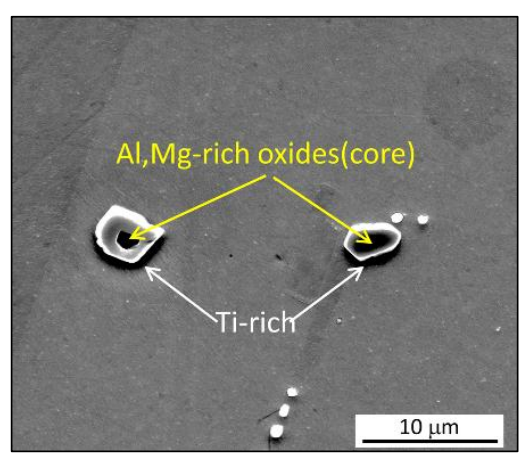

a) Ti-rich carbides ( $\mathrm{TiC})$

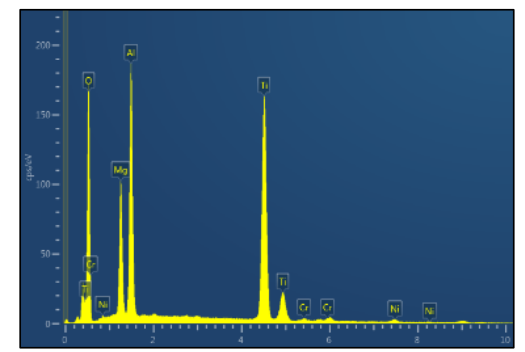

d) Spectrum core of Ti-rich carbides
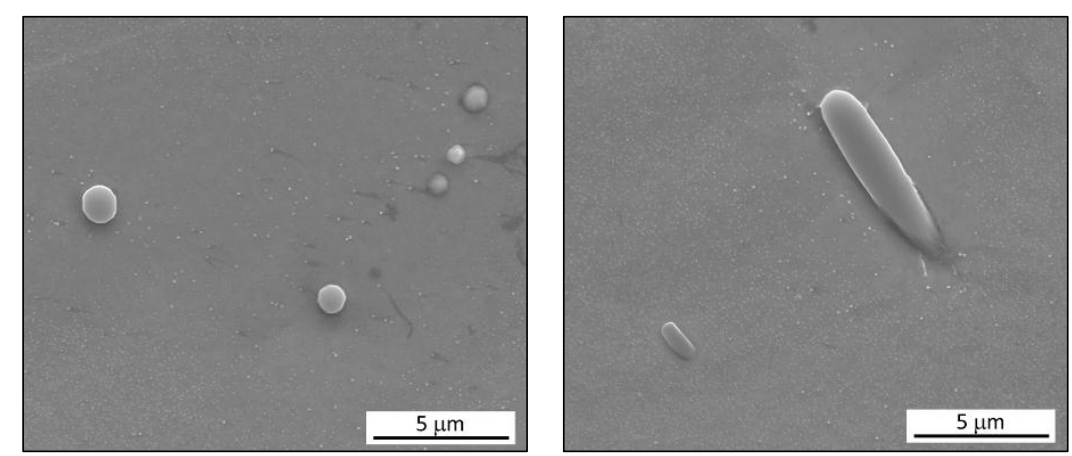

b, c) Cr-rich carbides: Globular and elongated carbides $\left(\mathrm{Cr}_{7} \mathrm{C}_{3}\right)$ in $\gamma$-matrix

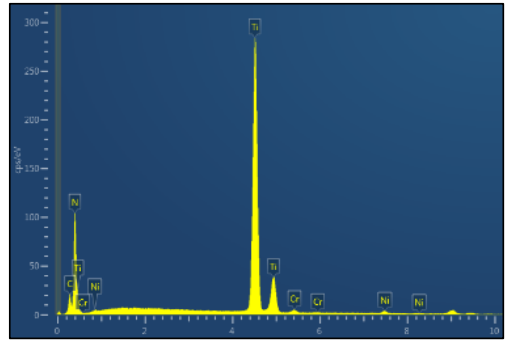

e) Spectrum of Ti-rich carbides

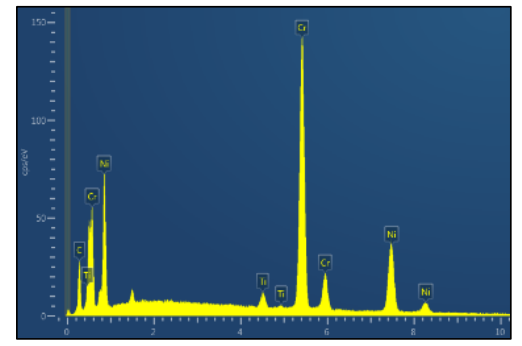

f) Spectrum of $\mathrm{Cr}$-rich carbides

FIGURE 4. TYPE OF CARBIDES IN NIMONIC 8OA IN AS-RECEIVED CONDITION, INCLUDIND EDS ANALYSIS

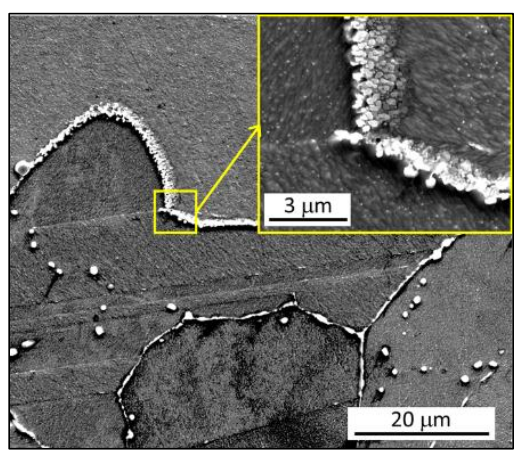

a) $950{ }^{\circ} \mathrm{C}$

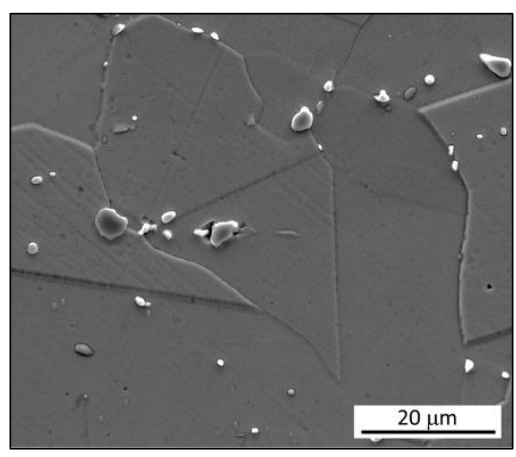

b) $1050{ }^{\circ} \mathrm{C}$

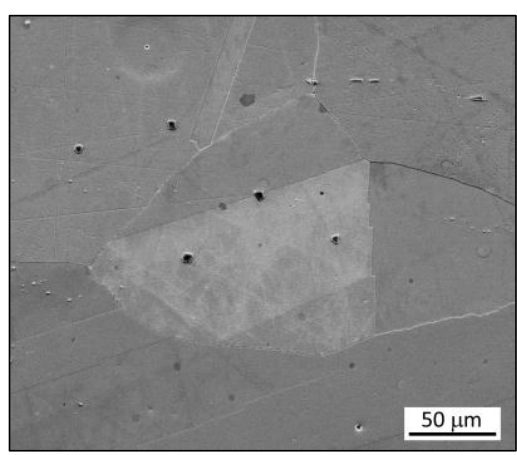

c) $1150{ }^{\circ} \mathrm{C}$

FIGURE 5. MICROSTRUCTURAL ANALYSIS IN THE AS-PREFORGED CONDITION

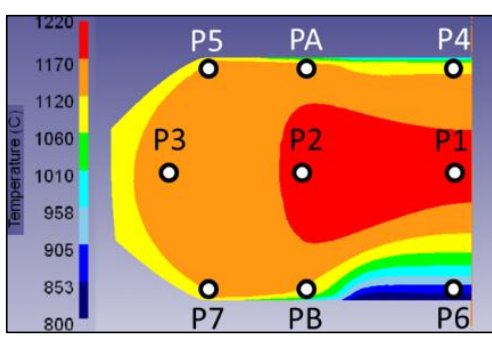

a) Temperature distribution

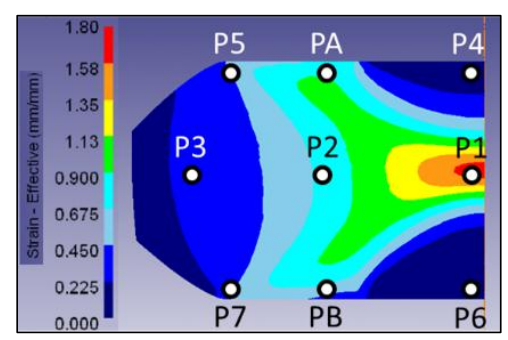

b) Strain distribution

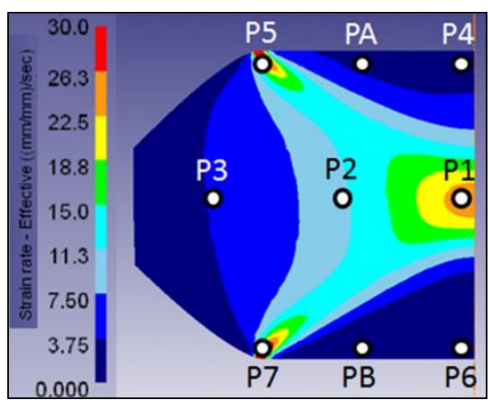

c) Strain rate distribution 


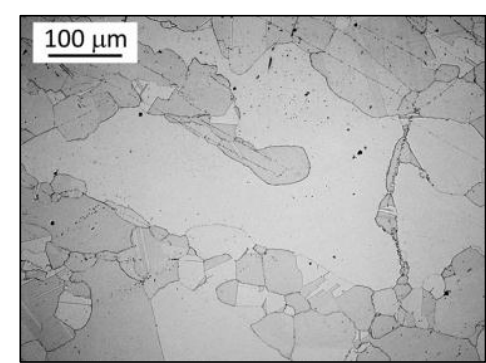

d) P5 $\left(\varepsilon_{\mathrm{P} 5} \approx 0.4 ; \dot{\varepsilon}_{P 5} \approx 30 \mathrm{~s}^{-1}\right)$

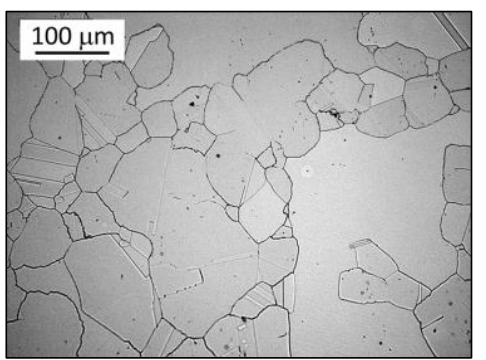

g) $\mathrm{P} 3\left(\varepsilon_{\mathrm{P} 3} \approx 0.3 ; \dot{\varepsilon}_{P 3} \approx 4 \mathrm{~s}^{-1}\right)$

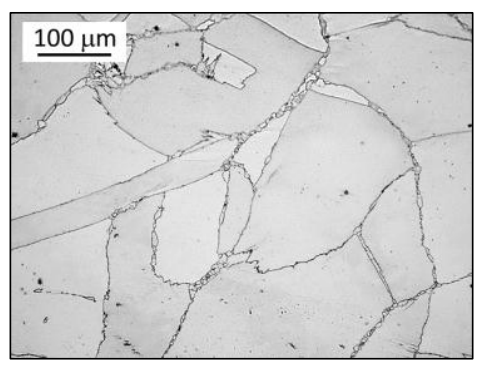

j) $\mathrm{P} 7\left(\varepsilon_{\mathrm{P} 7} \approx 0.4 ; \dot{\varepsilon}_{P 7} \approx 30 \mathrm{~s}^{-1}\right)$

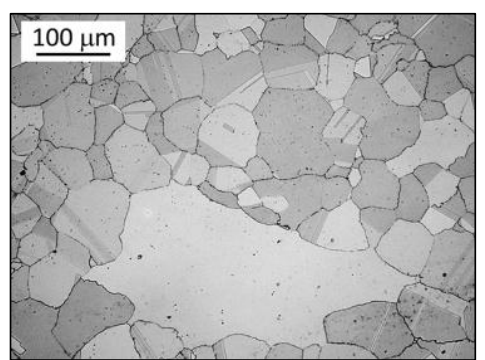

e) PA $\left(\varepsilon \mathrm{PA} \approx 0.8 ; \dot{\varepsilon}_{P A} \approx 3 \mathrm{~s}^{-1}\right)$

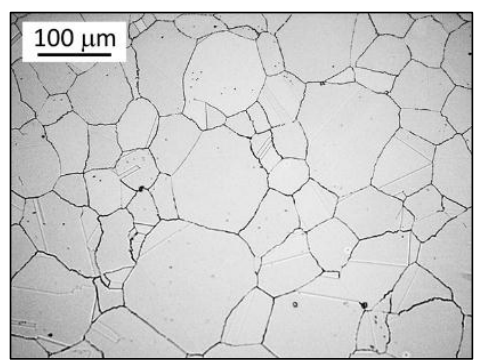

h) P2 $\left(\varepsilon_{\mathrm{P} 2} \approx 0.7 ; \dot{\varepsilon}_{P 2} \approx 10 \mathrm{~s}^{-1}\right)$

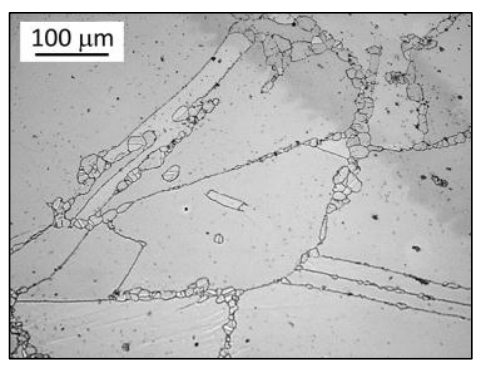

k) $\mathrm{PB}\left(\varepsilon_{\mathrm{PB}} \approx 0.6 ; \dot{\varepsilon}_{P B} \approx 3 \mathrm{~s}^{-1}\right)$

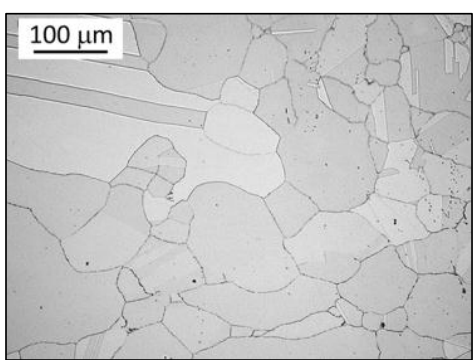

f) $\mathrm{P} 4\left(\varepsilon_{\mathrm{P} 4} \approx 0.1 ; \dot{\varepsilon}_{\mathrm{P} 4} \approx 2 \mathrm{~s}^{-1}\right)$

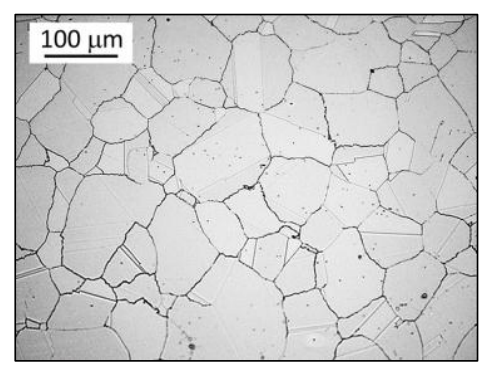

i) $\mathrm{P} 1\left(\varepsilon_{\mathrm{P} 1} \approx 1.8 ; \dot{\varepsilon}_{P 1} \approx 25 \mathrm{~s}^{-1}\right)$

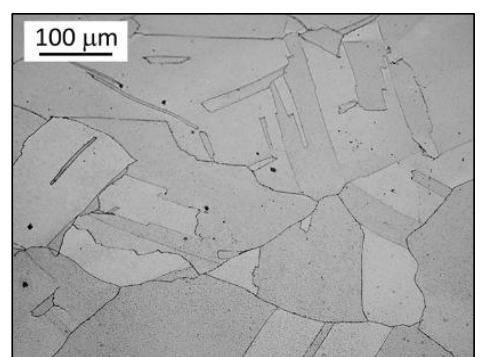

I) $\mathrm{P} 6\left(\varepsilon_{\mathrm{P} 6} \approx 0.1 ; \dot{\varepsilon}_{\mathrm{P} 6} \approx 2 \mathrm{~s}^{-1}\right)$

FIGURE 6. OPTICAL MICROGRAPHS FROM DIFFERENT REGIONS OF DTC FORGED AT $1150^{\circ} \mathrm{C}$ (AS-FORGED CONDITION)

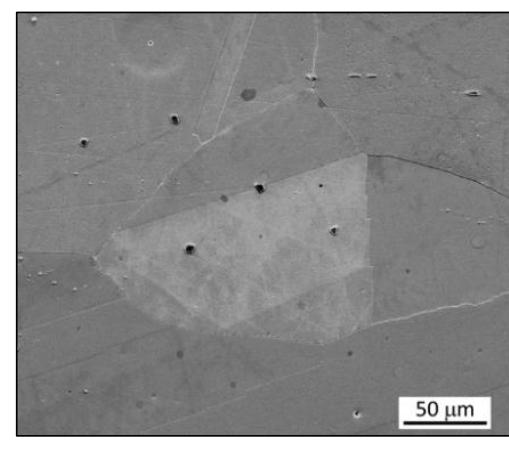

a) As-preforged condition

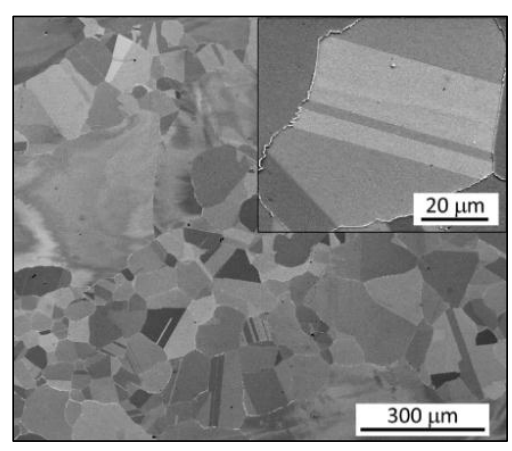

b) Region 4 of DTC

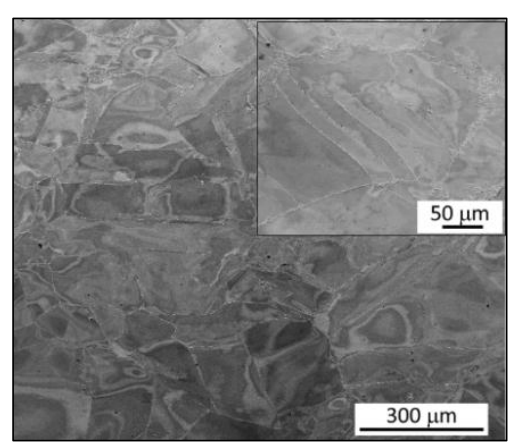

c) Region 6 of DTC

FIGURE 7. SEM MICROGRAPHS OF AS-PREFORGED VS. AS-FORGED CONDITION (DTC FORGED AT $1150^{\circ} \mathrm{C}$ ) 


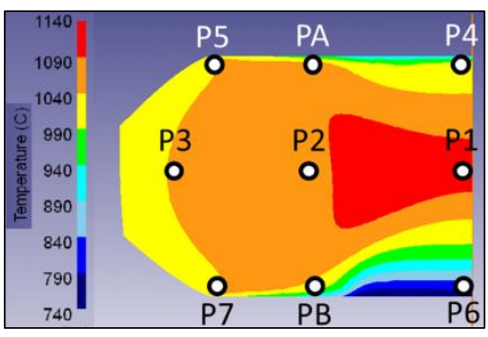

a) Temperature distribution

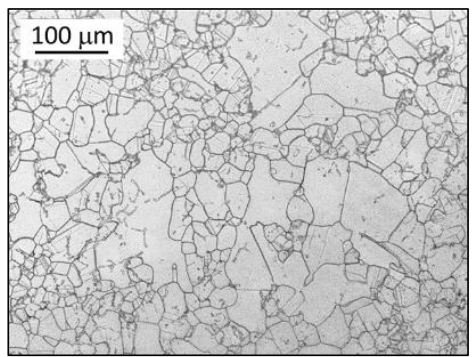

d) P5 $\left(\varepsilon_{\mathrm{P} 5} \approx 0.4 ; \dot{\varepsilon}_{P 5} \approx 30 \mathrm{~s}^{-1}\right)$

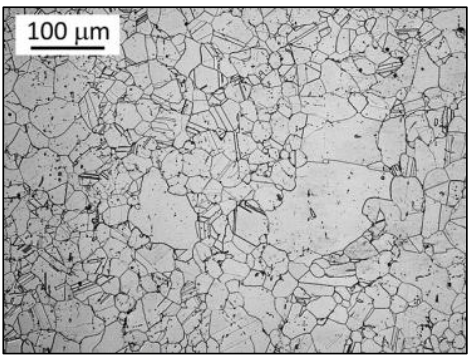

g) P3 $\left(\varepsilon_{\mathrm{P} 3} \approx 0.2 ; \dot{\varepsilon}_{P 3} \approx 4 \mathrm{~s}^{-1}\right)$

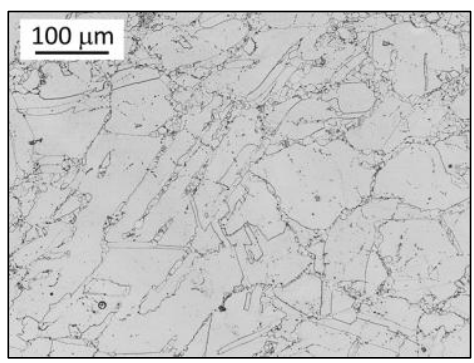

j) $\mathrm{P} 7\left(\varepsilon_{\mathrm{P} 7} \approx 0.4 ; \dot{\varepsilon}_{P 7} \approx 30 \mathrm{~s}^{-1}\right)$

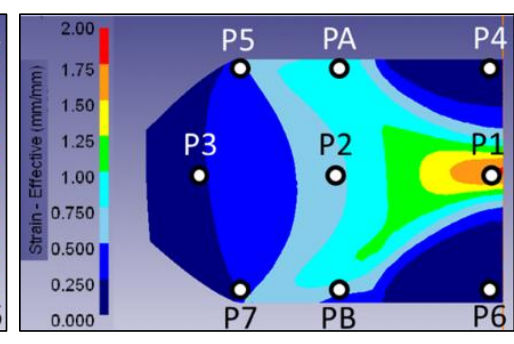

b) Strain distribution

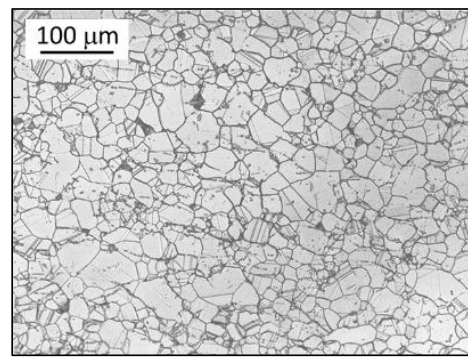

e) $\mathrm{PA}\left(\varepsilon \mathrm{PA} \approx 0.8 ; \dot{\varepsilon}_{P A} \approx 3 \mathrm{~s}^{-1}\right)$

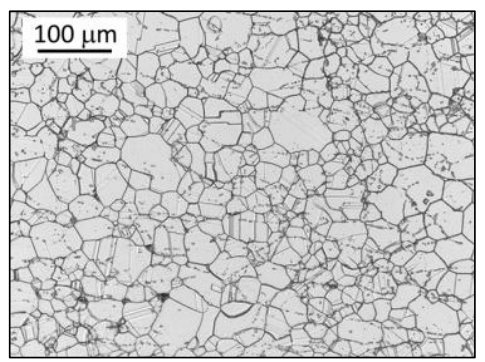

h) $\mathrm{P} 2\left(\varepsilon_{\mathrm{P} 2} \approx 0.7 ; \dot{\varepsilon}_{P 2} \approx 10 \mathrm{~s}^{-1}\right)$

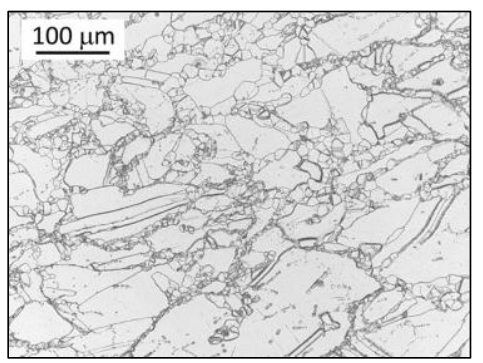

k) $\mathrm{PB}\left(\varepsilon_{\mathrm{PB}} \approx 0.7 ; \dot{\varepsilon}_{P B} \approx 3 \mathrm{~s}^{-1}\right)$

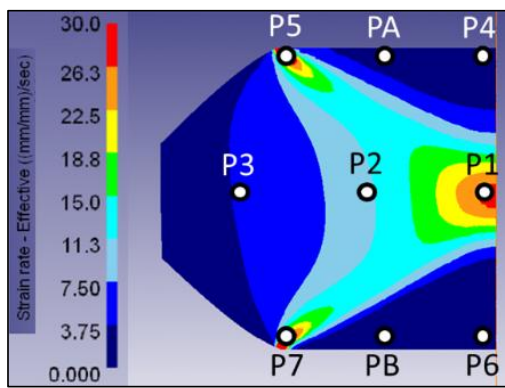

c) Strain rate distribution

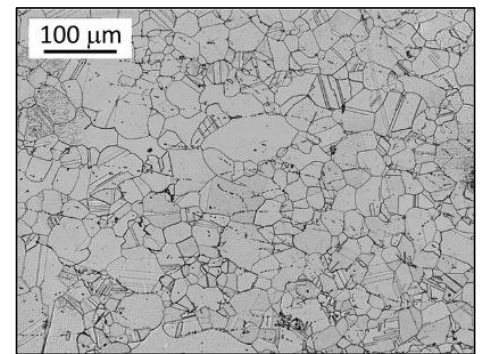

f) P4 $\left(\varepsilon \mathrm{P} 4 \approx 0.1 ; \dot{\varepsilon}_{P 4} \approx 2 \mathrm{~s}^{-1}\right)$

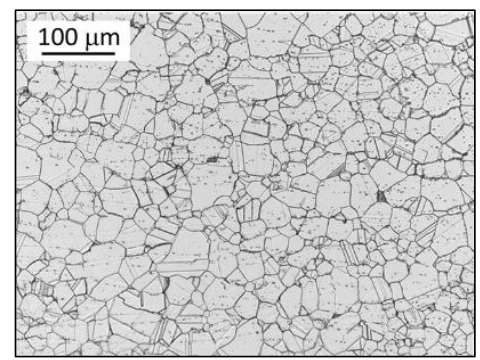

i) $\mathrm{P} 1\left(\varepsilon_{\mathrm{P} 1} \approx 1.8 ; \dot{\varepsilon}_{P 1} \approx 30 \mathrm{~s}^{-1}\right)$

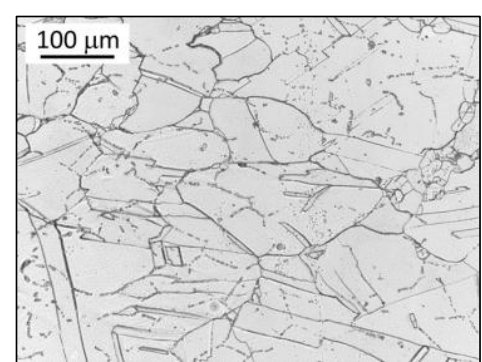

I) P6 ( $\left.\varepsilon_{\mathrm{P} 6} \approx 0.1 ; \dot{\varepsilon}_{P 6} \approx 2 \mathrm{~s}^{-1}\right)$

FIGURE 8. OPTICAL MICROGRAPHS FROM DIFFERENT REGIONS OF DTC FORGED AT $1050^{\circ} \mathrm{C}$ (AS-FORGED CONDITION)

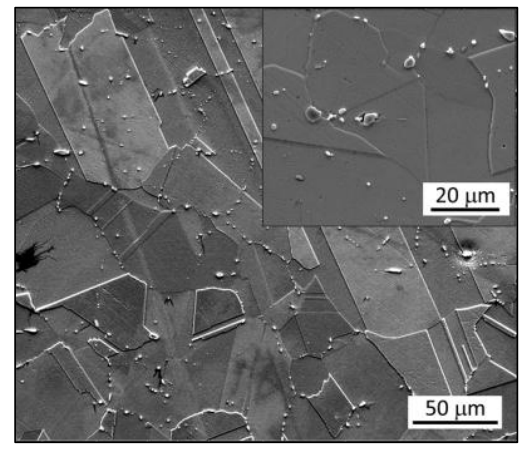

a) As-preforged condition

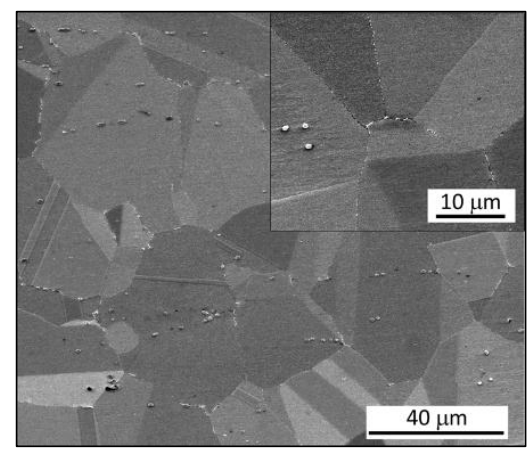

b) Region 1 of DTC

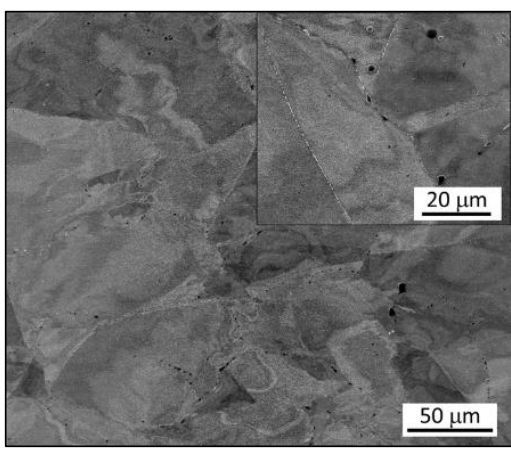

c) Region 6 of DTC

FIGURE 9. SEM MICROGRAPHS OF AS-PREFORGED VS. AS-FORGED CONDITION (DTC FORGED AT $1050^{\circ} \mathrm{C}$ ) 


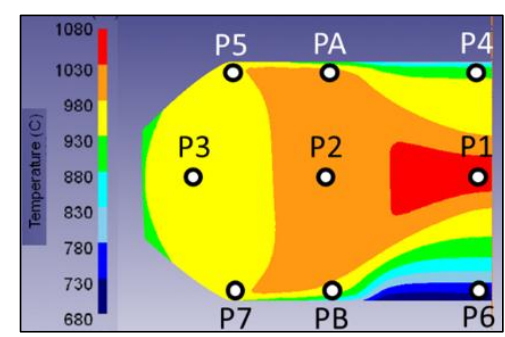

a) Temperature distribution

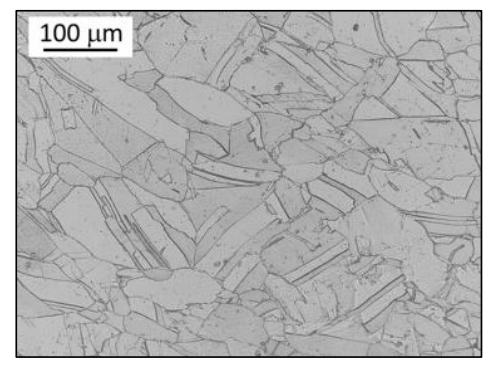

d) P5 $\left(\varepsilon \mathrm{P5} \approx 0.4 ; \dot{\varepsilon}_{P 5} \approx 30 \mathrm{~s}^{-1}\right)$

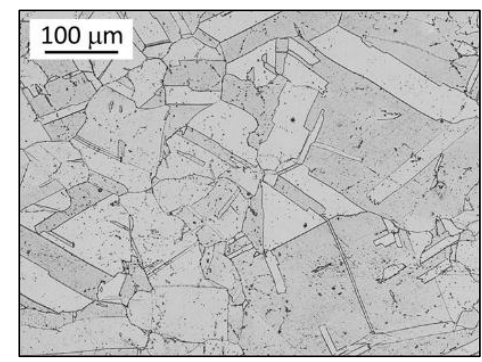

g) P3 $\left(\varepsilon_{\mathrm{P} 3} \approx 0.2 ; \dot{\varepsilon}_{P 3} \approx 3 \mathrm{~s}^{-1}\right)$

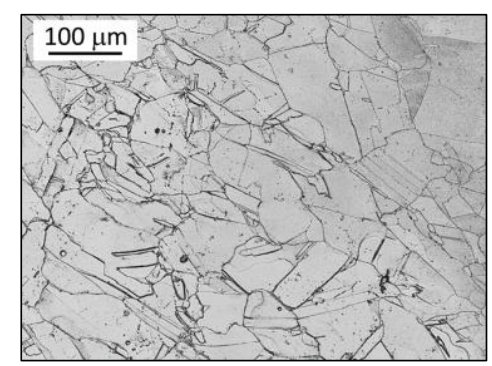

j) $\mathrm{P} 7\left(\varepsilon_{\mathrm{P} 7} \approx 0.4 ; \dot{\varepsilon}_{P 7} \approx 30 \mathrm{~s}^{-1}\right)$

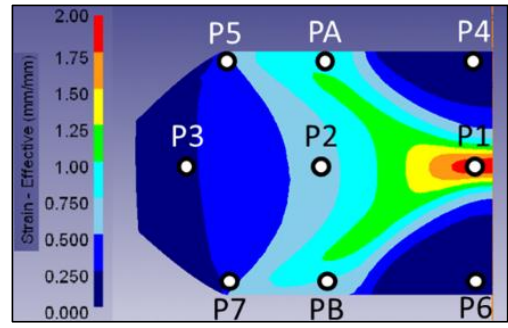

b) Strain distribution

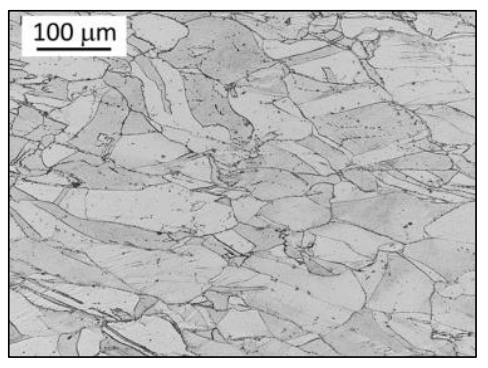

e) $\mathrm{PA}\left(\varepsilon \mathrm{PA} \approx 0.8 ; \dot{\varepsilon}_{P A} \approx 3 \mathrm{~s}^{-1}\right)$

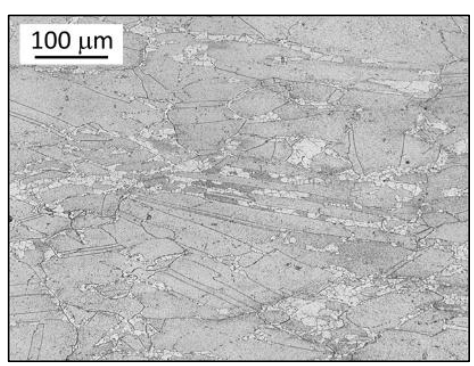

h) $\mathrm{P} 2\left(\varepsilon_{\mathrm{P} 2} \approx 0.7 ; \dot{\varepsilon}_{\mathrm{P} 2} \approx 10 \mathrm{~s}^{-1}\right)$

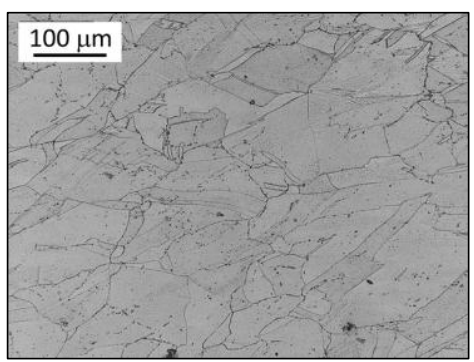

k) $\mathrm{PB}\left(\varepsilon_{\mathrm{PB}} \approx 0.7 ; \dot{\varepsilon}_{P B} \approx 3 \mathrm{~s}^{-1}\right)$

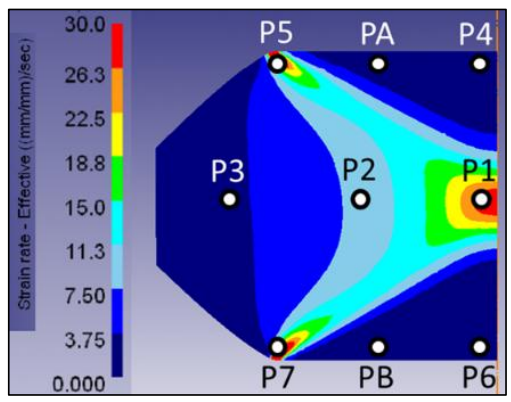

c) Strain rate distribution

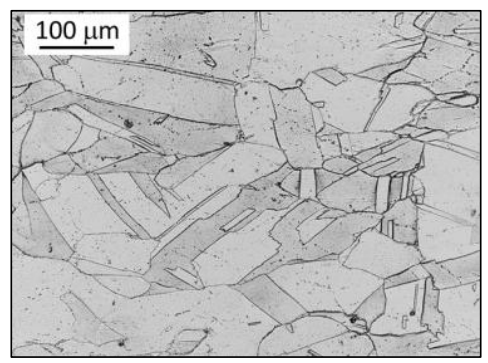

f) $\mathrm{P} 4\left(\varepsilon \mathrm{P} 4 \approx 0.1 ; \dot{\varepsilon}_{P 4} \approx 2 \mathrm{~s}^{-1}\right)$

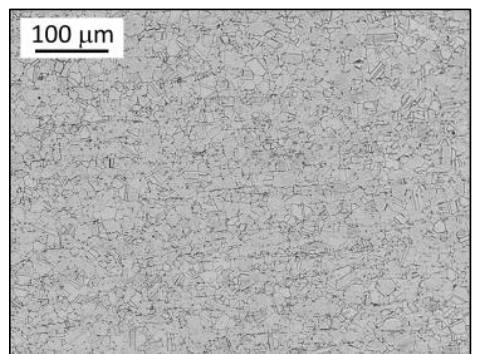

i) $\mathrm{P} 1\left(\varepsilon_{\mathrm{P} 1} \approx 2 ; \dot{\varepsilon}_{\mathrm{P} 1} \approx 30 \mathrm{~s}^{-1}\right)$

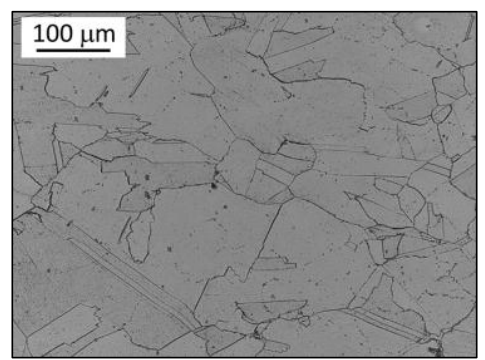

I) $\mathrm{P} 6\left(\varepsilon_{\mathrm{P} 6} \approx 0.1 ; \dot{\varepsilon}_{P 6} \approx 2 \mathrm{~s}^{-1}\right)$

FIGURE 10. OPTICAL MICROGRAPHS FROM DIFFERENT REGIONS OF DTC FORGED AT $950^{\circ} \mathrm{C}$ (AS-FORGED CONDITION) 


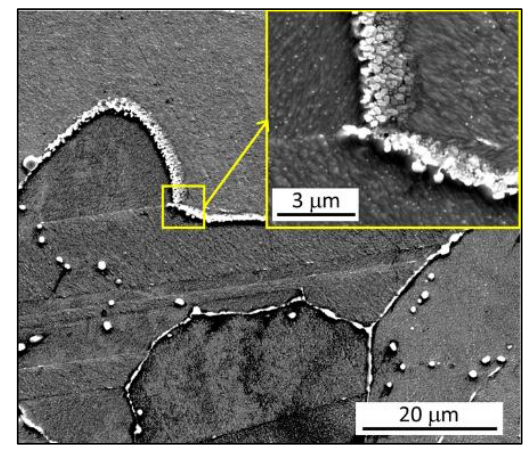

a) As-preforged condition

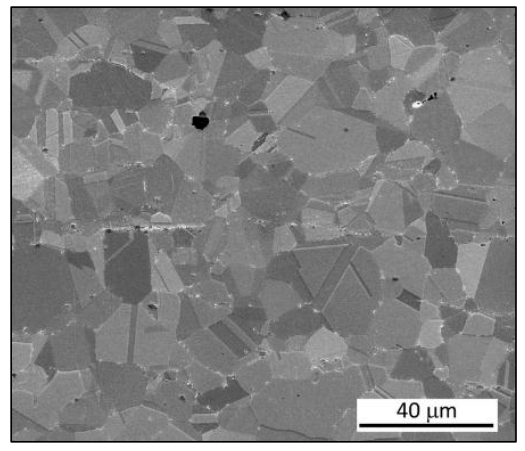

b) Region 1 of DTC

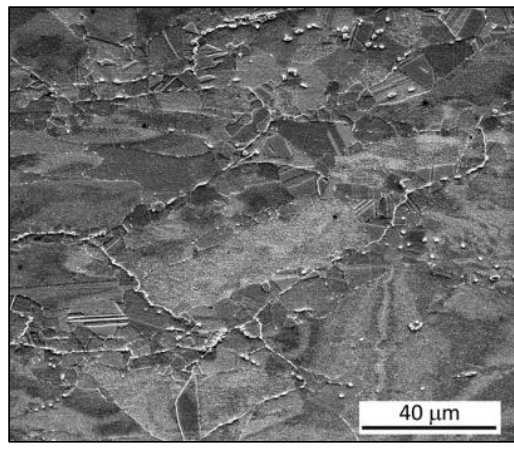

c) Region 2 of DTC

FIGURE 11. SEM MICROGRAPHS OF AS-PREFORGED VS. AS-FORGED CONDITION (DTC FORGED AT $950^{\circ} \mathrm{C}$ )

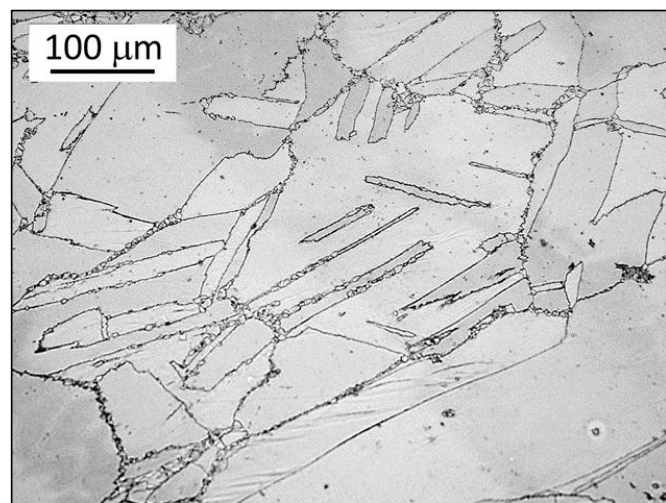

a)

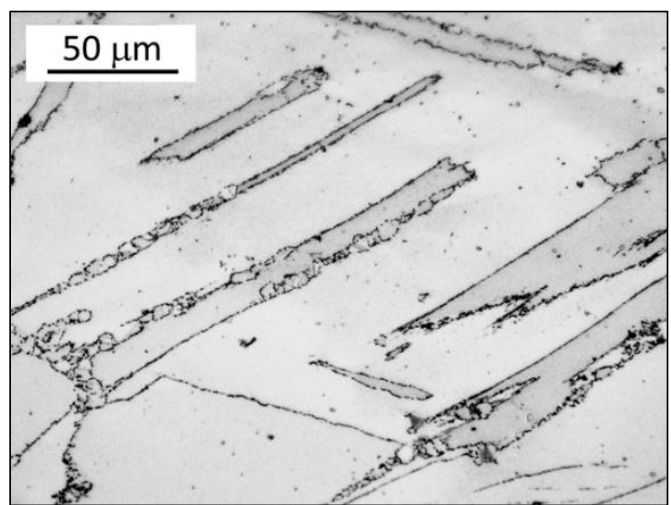

b)

FIGURE 12. OPTICAL MICROGRAPHS OF NIMONIC 8OA FROM THE REGION PB OF DTC FORGED AT $1150^{\circ} \mathrm{C}$

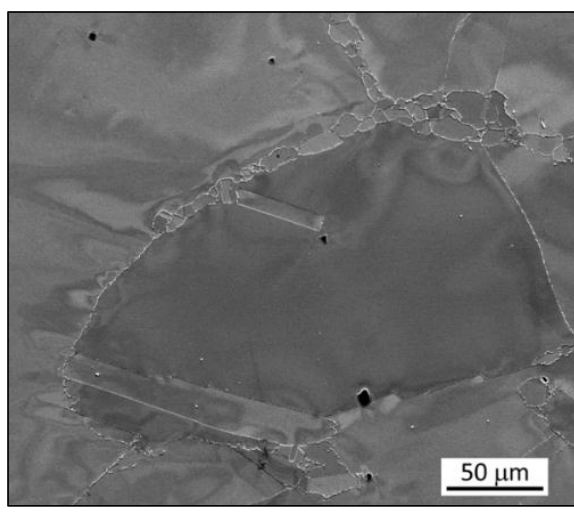

a) Nucleation and growth of DRX grains in grain boundaries of deformed grains

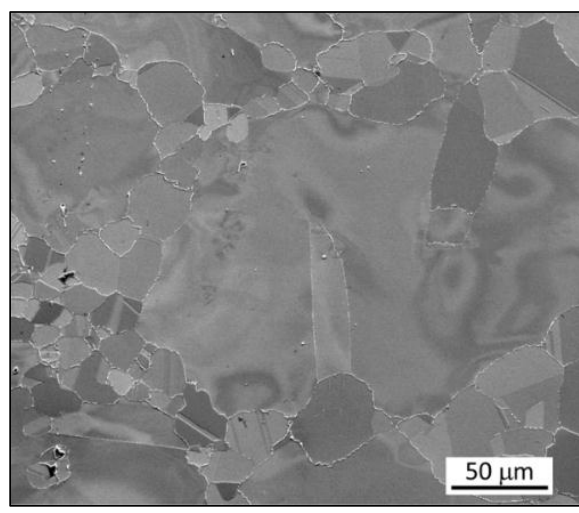

b) Further growth of DRX grains

FIGURE 13. SEM MICROGRAPHS OF NIMONIC 8OA FROM THE REGION PB OF DTC FORGED AT $1150^{\circ} \mathrm{C}$ 


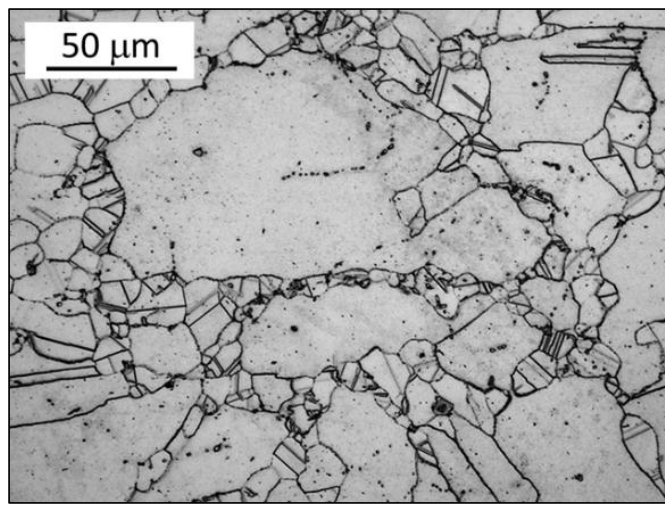

FIGURE 14. REGION PB - NIMONIC 80A DTC FORGED AT

$1050^{\circ} \mathrm{C}$

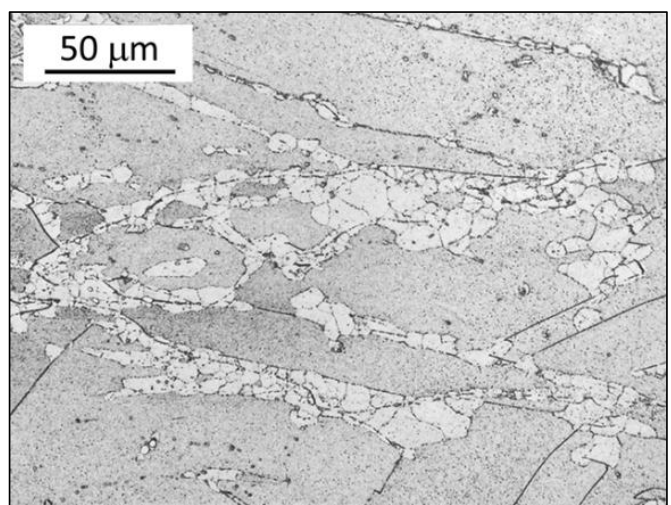

FIGURE 15. REGION 2 - NIMONIC 80A DTC FORGED

AT $950^{\circ} \mathrm{C}$

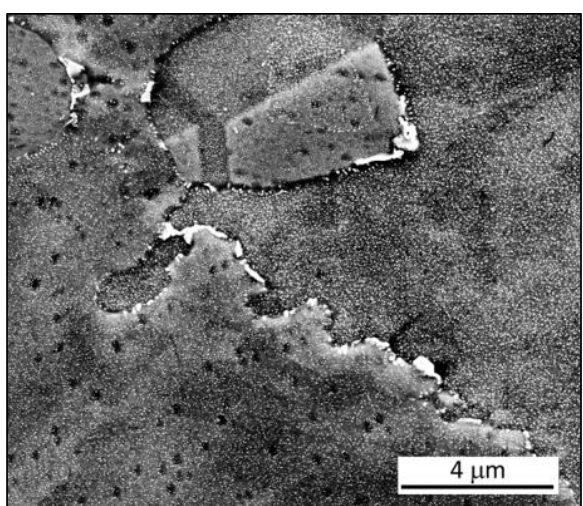

a) Region PB - DTC $1050^{\circ} \mathrm{C}$

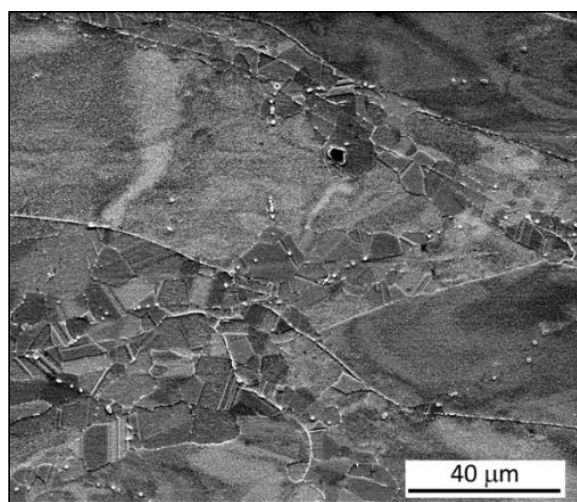

b) Region $2-\mathrm{DTC}$ at $950^{\circ} \mathrm{C}$

FIGURE 16. FORMATION OF BULGES AT SERRATED GRAIN BOUNDARIES, A); AND LARGE FRACTION OF TWIN BOUNDARES ON NEW DRX GRAINS, B).

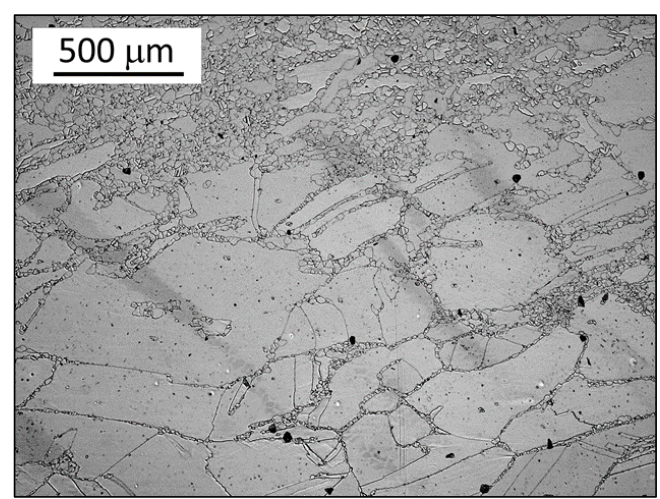

a)

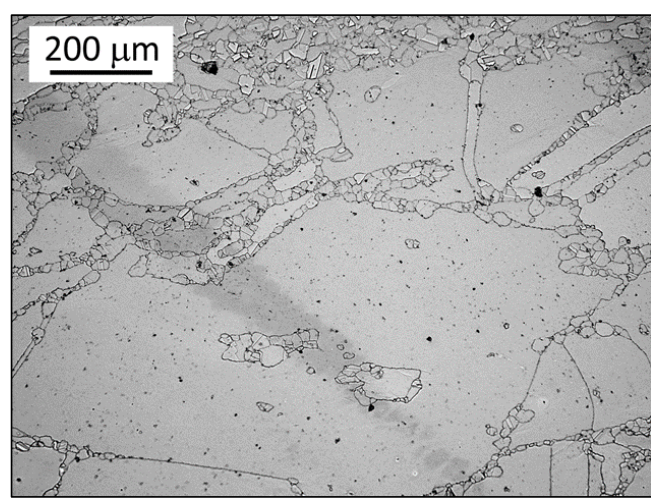

b) 


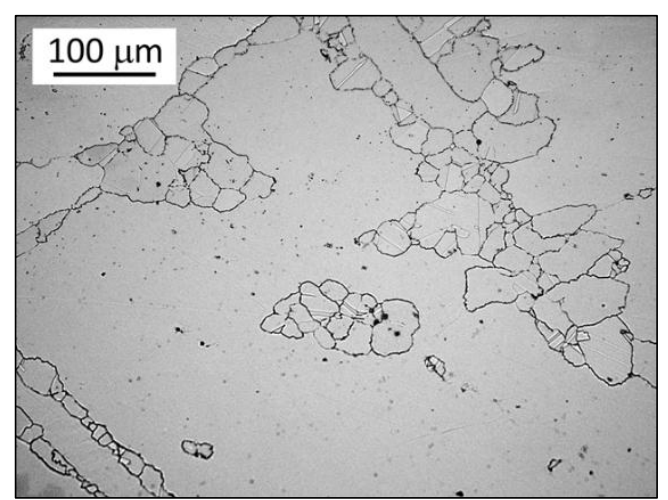

C)

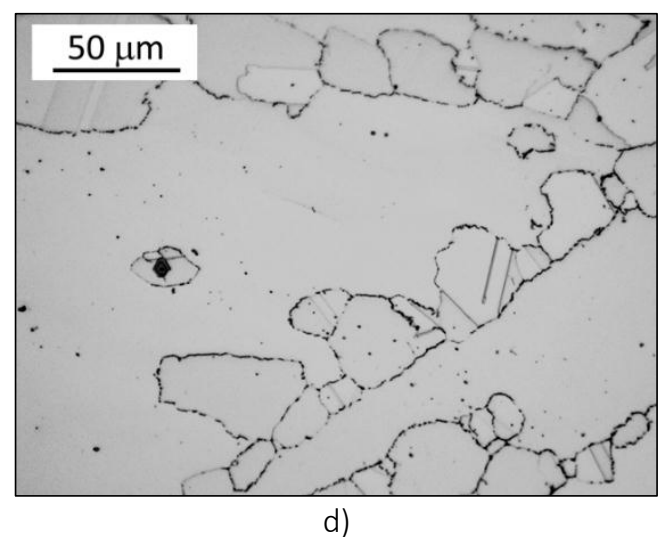

d)

FIGURE 17. GRAIN STRUCTURES OF REGION PB FROM DTC FORGED AT $1150^{\circ} \mathrm{C}$

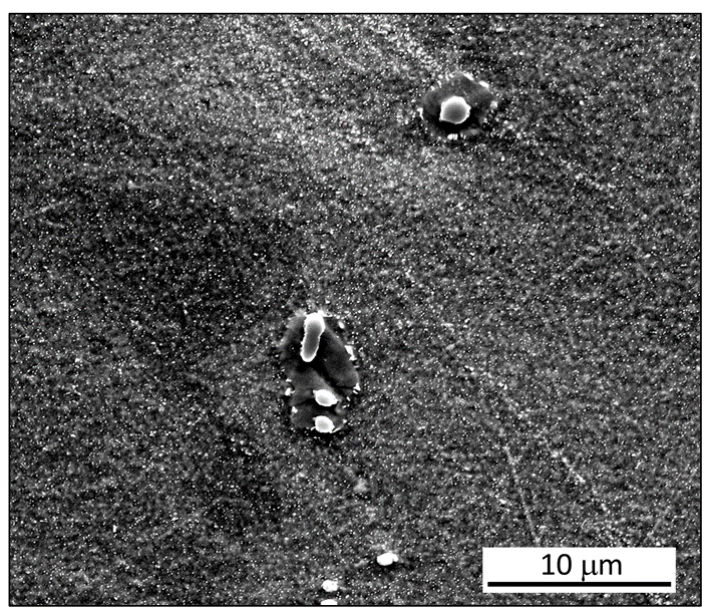

a)

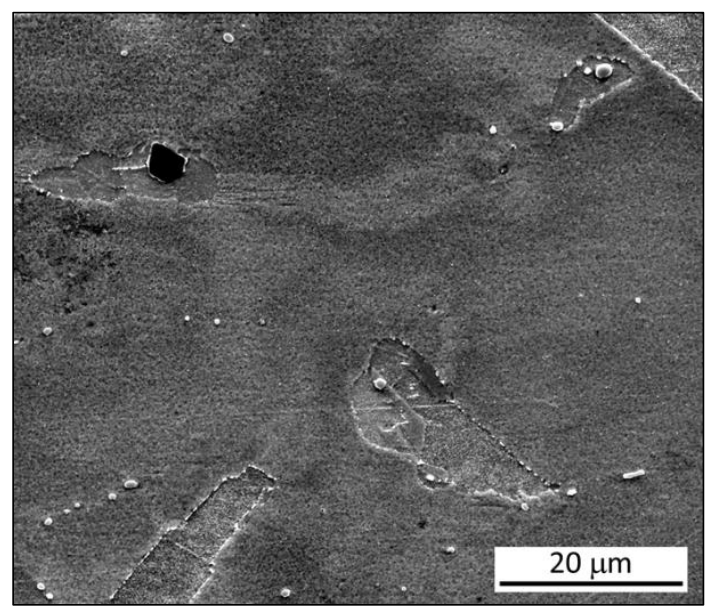

b)

FIGURE 18. NUCLEATION OF NEW GRAINS ON CARBIDES LOCATED IN THE INTERIOR OF DEFORMED GRAINS BY PARTICLE-STIMULATED NUCLEATION MECHANISM (PSN) - REGION 2 OF NIMONIC 8OA DTC FORGED AT $950^{\circ} \mathrm{C}$ 


\section{TABLE CAPTIONS}

TABLE 1. PHASES OBSERVED IN NIMONIC 80A SUPERALLOY

TABLE 2. CHEMICAL COMPOSITION OF THE SUPPLIED NIMONIC 80A BAR

TABLE 3. STRAIN AND STRAIN RATE DISTRIBUTION OF THE 9 SELECTED REGIONS OF HOT FORGED DOUBLE CONES

TABLE 1. PHASES OBSERVED IN NIMONIC 80A SUPERALLOY (VOICE AND FAULKNER, 1985) (DONACHIE AND DONACHIE, 2002).

\begin{tabular}{|c|c|c|c|}
\hline Phase & $\begin{array}{c}\text { Crystal } \\
\text { structure }\end{array}$ & Formula & Solvus temperature \\
\hline $\mathrm{MC}$ & Cubic & $\mathrm{TiC}$ & $T>1250{ }^{\circ} \mathrm{C}$ \\
\hline $\mathrm{M}_{7} \mathrm{C}_{3}$ & Hexagonal & $\mathrm{Cr}_{7} \mathrm{C}_{3}$ & $1095{ }^{\circ} \mathrm{C}<T<1150{ }^{\circ} \mathrm{C}$ \\
\hline $\mathrm{M}_{23} \mathrm{C}_{6}$ & $\mathrm{FCC}$ & $\mathrm{C}_{23} \mathrm{C}_{6}(\mathrm{Cr}, \mathrm{Fe}, \mathrm{W}, \mathrm{Mo})_{23} \mathrm{C}_{6}$ & $1050{ }^{\circ} \mathrm{C}<T<1095^{\circ} \mathrm{C}$ \\
\hline$\gamma^{\prime}$ & $\mathrm{FCC}$ & $\mathrm{Ni}_{3} \mathrm{AlNi}(\mathrm{Al}, \mathrm{Ti})$ & $T>950^{\circ} \mathrm{C}$ \\
\hline
\end{tabular}

TABLE 2. CHEMICAL COMPOSITION OF THE SUPPLIED NIMONIC 80A BAR

\begin{tabular}{|c|c|c|c|c|c|c|c|c|c|c|}
\hline C & $\mathrm{Si}$ & $\mathrm{Mn}$ & $\mathrm{Al}$ & $\mathrm{B}$ & $\mathrm{Co}$ & $\mathrm{Cr}$ & $\mathrm{Cu}$ & $\mathrm{Fe}$ & $\mathrm{Ti}$ & $\mathrm{Ni}$ \\
\hline 0.053 & 0.07 & 0.03 & 1.49 & 0.003 & 0.29 & 19.55 & 0.02 & 0.27 & 2.46 & 75.78 \\
\hline
\end{tabular}

TABLE 3. STRAIN AND STRAIN RATE DISTRIBUTION OF 9 SELECTED REGIONS OF HOT FORGED DOUBLE CONES

\begin{tabular}{|c|c|c|c|c|c|c|c|}
\hline \multirow{2}{*}{\multicolumn{2}{|c|}{ Position - Region }} & \multicolumn{2}{|c|}{ DTC $1150^{\circ} \mathrm{C}$} & \multicolumn{2}{|c|}{ DTC $1050{ }^{\circ} \mathrm{C}$} & \multicolumn{2}{|c|}{ DTC $950^{\circ} \mathrm{C}$} \\
\hline & & Strain & Strain rate & Strain & Strain rate & Strain & Strain rate \\
\hline \multirow{3}{*}{$\begin{array}{l}\text { TOP } \\
\text { TOOL }\end{array}$} & P4 & $\varepsilon \approx 0.1$ & $\dot{\varepsilon} \approx 2 \mathrm{~s}^{-1}$ & $\varepsilon \approx 0.1$ & $\dot{\varepsilon} \approx 2 \mathrm{~s}^{-1}$ & $\varepsilon \approx 0.1$ & $\dot{\varepsilon} \approx 2 \mathrm{~s}^{-1}$ \\
\hline & PA & $\varepsilon \approx 0.8$ & $\dot{\varepsilon} \approx 3 \mathrm{~s}^{-1}$ & $\varepsilon \approx 0.8$ & $\dot{\varepsilon} \approx 3 \mathrm{~s}^{-1}$ & $\varepsilon \approx 0.8$ & $\dot{\varepsilon} \approx 3 \mathrm{~s}^{-1}$ \\
\hline & P5 & $\varepsilon \approx 0.4$ & $\dot{\varepsilon} \approx 30 \mathrm{~s}^{-1}$ & $\varepsilon \approx 0.4$ & $\dot{\varepsilon} \approx 30 \mathrm{~s}^{-1}$ & $\varepsilon \approx 0.4$ & $\dot{\varepsilon} \approx 30 \mathrm{~s}^{-1}$ \\
\hline \multirow{3}{*}{ CENTRE } & P1 & $\varepsilon \approx 1.8$ & $\dot{\varepsilon} \approx 25 \mathrm{~s}^{-1}$ & $\varepsilon \approx 1.8$ & $\dot{\varepsilon} \approx 30 \mathrm{~s}^{-1}$ & $\varepsilon \approx 2.0$ & $\dot{\varepsilon} \approx 30 \mathrm{~s}^{-1}$ \\
\hline & $\mathrm{P} 2$ & $\varepsilon \approx 0.7$ & $\dot{\varepsilon} \approx 10 \mathrm{~s}^{-1}$ & $\varepsilon \approx 0.7$ & $\dot{\varepsilon} \approx 10 \mathrm{~s}^{-1}$ & $\varepsilon \approx 0.7$ & $\dot{\varepsilon} \approx 10 \mathrm{~s}^{-1}$ \\
\hline & P3 & $\varepsilon \approx 0.3$ & $\dot{\varepsilon} \approx 4 \mathrm{~s}^{-1}$ & $\varepsilon \approx 0.2$ & $\dot{\varepsilon} \approx 4 \mathrm{~s}^{-1}$ & $\varepsilon \approx 0.2$ & $\dot{\varepsilon} \approx 3 \mathrm{~s}^{-1}$ \\
\hline \multirow{3}{*}{$\begin{array}{c}\text { BOTTOM } \\
\text { TOOL }\end{array}$} & P6 & $\varepsilon \approx 0.1$ & $\dot{\varepsilon} \approx 2 \mathrm{~s}^{-1}$ & $\varepsilon \approx 0.1$ & $\dot{\varepsilon} \approx 2 \mathrm{~s}^{-1}$ & $\varepsilon \approx 0.1$ & $\dot{\varepsilon} \approx 2 \mathrm{~s}^{-1}$ \\
\hline & PB & $\varepsilon \approx 0.6$ & $\dot{\varepsilon} \approx 3 \mathrm{~s}^{-1}$ & $\varepsilon \approx 0.7$ & $\dot{\varepsilon} \approx 3 \mathrm{~s}^{-1}$ & $\varepsilon \approx 0.7$ & $\dot{\varepsilon} \approx 3 \mathrm{~s}^{-1}$ \\
\hline & P7 & $\varepsilon \approx 0.4$ & $\dot{\varepsilon} \approx 30 \mathrm{~s}^{-1}$ & $\varepsilon \approx 0.4$ & $\dot{\varepsilon} \approx 30 \mathrm{~s}^{-1}$ & $\varepsilon \approx 0.4$ & $\dot{\varepsilon} \approx 30 \mathrm{~s}^{-1}$ \\
\hline
\end{tabular}


Page 30 